2. To: (Receiving Organization) Distribution

5. Proj./Prog./Dept./Divi: TWRS Safety Issue Resolution 8. Originator Remarks:

OWFSB Recommendation 93-5, Milestone 5.4.3.1.b, requires the submitral of a sumary of lightning issues with respect to tank waste, including recommendations for mitigative actions.

11. Receiver Remarks:

\author{
3. From: (originating organization) \\ TWRS Safety Issue Resolution \\ 6. Cog. Engr.: \\ J. J. Zach
}

\author{
4. Related EDT No. \\ 7. Purchase Order No.: \\ 9. Equip-/Component No.:
}

10. System/Bldg./Facility:

12. Major Assm. Dwg. No.:

13. Permit/Permit Application Na.:

14. Required Response Date:

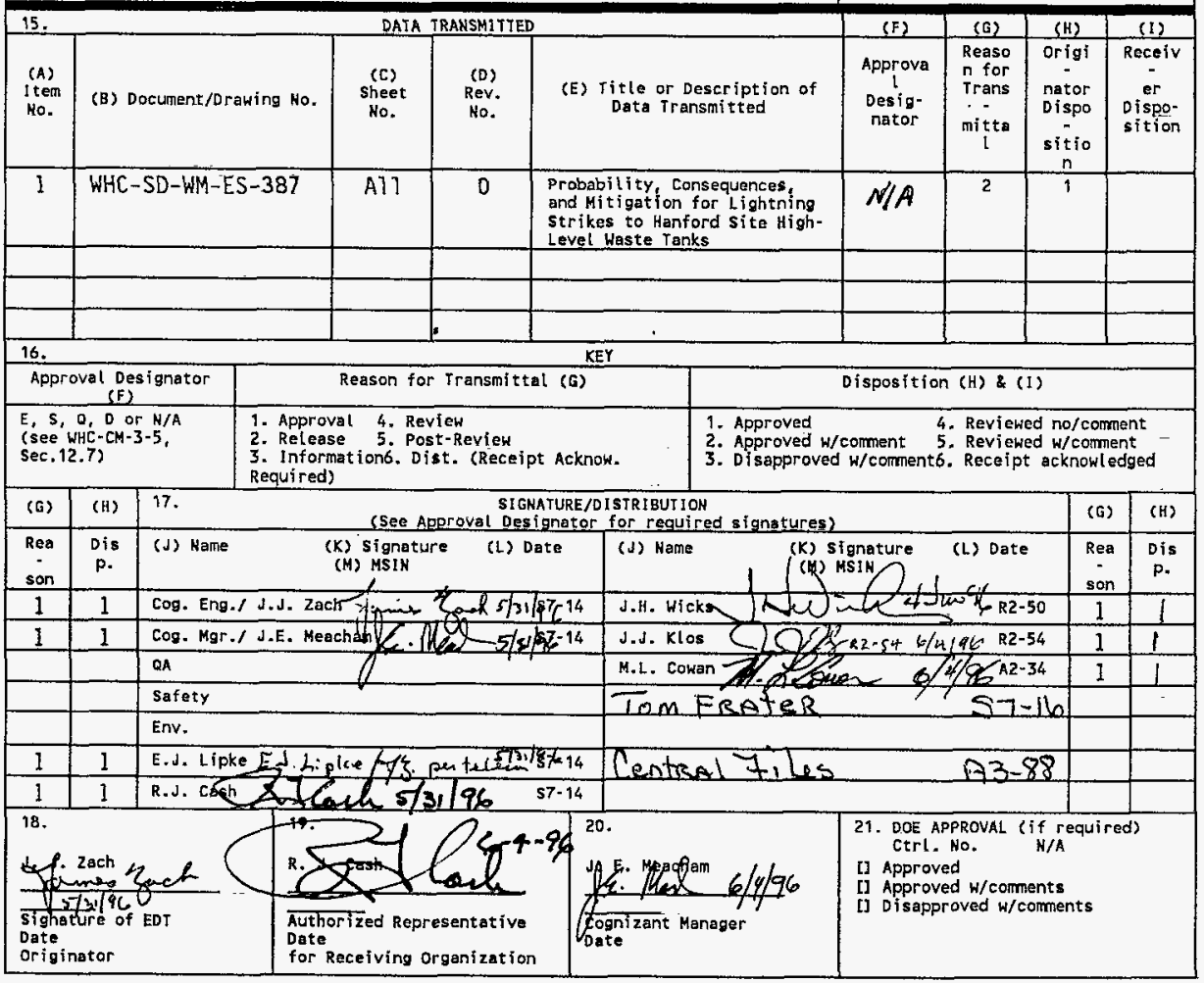




\title{
PROBABILITY, CONSEOUENCES, AND MITIGATION FOR LIGHTNING STRIKES TO HANFORD SITE HIGH-LEVEL WASTE TANKS
}

\section{J. J. Zach}

Westinghouse Hanford Company, Richland, WA 99352

U.S. Department of Energy Contract DE-AC06-87RL10930

\author{
EOT/ECN: EDT 613755 UC: 2030 \\ Org Code: $74 \mathrm{E} 10 \quad$ Charge Code: E45379 \\ B\&R Code: Total Pages: $7 \%$
}

Key Words: Lightning, Lightning Mitigation, Lightning Frequency

Abstract: The purpose of this report is to summarize selected

1 ightning issues concerning the Hanford Waste Tanks. These issues. include the probability of a lightning discharge striking the area immediateiy adjacent to a tank including a riser, the consequences of significant energy deposition from a Tightning strike in a tank, and mitigating actions that have been or are being taken. The major conclusion of this report is that the probability of a lightning strike depositing sufficient energy in a tank to cause an effect on employees or the pubilic is unlikely; but there are insufficlent, quantitative data on the tanks and waste to prove that. Protection, such as grounding of risers and air terminals on existing light poles, is recommended.

IRADEMARK DISCLAIMER. Referencs herein to any specific comercial product, process, or service by trade name, trademark, manufacturer, or otherwise, does not necessarily constitute or imply its endorsement, recommendation, or favoring by the United states Government or any agency thereof or its contractors or subcontractors.

Printed in the United states of America. To obtain copies of this document, contact: WHC/BCS Document Control Services, P.O. BOX 1970, Mailstop H6-08, Richland WA 99352, Phone (509) 372-2420; Fex (509) $376-4989$.
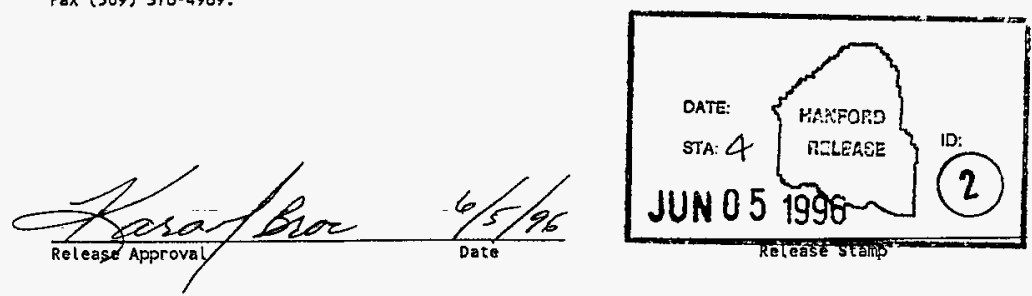

\section{Approved for Public Release}




\section{EXECUTIVE SUMMARY}

The purpose of this paper is to evaluate the probability and potential consequences of lightning strikes affecting the underground waste storage tanks at Hanford. It does not address Double-Contained Receiver Tanks (DCRTs). These results are used to determine the need for any corrective or mitigative actions in order to provide an acceptable level of safety.

Lightning strike probability is determined on the basis of lightning detection over a 10 year period, resulting in an assumed strike probability of $0.06 \mathrm{flash} / \mathrm{km}^{2} /$ year.

While the data support the determination of a strike probability, lightning behavior cannot be easily predicted. A quantitative assessment cannot be done now of the likelihood of specific behaviors or how lightning effects will propagate through the systems or equipment in the vicinity of a strike.

The results of this analysis demonstrate that lightning strikes on or near tanks have the potential of depositing energy in the waste. While it is demonstrated that energy deposited in the waste is reduced as the strike location becomes more removed from the direct tank area, a strike anywhere on the farm can affect a tank.

There are basically two lightning effects of concern: the ignition of flammable gas in the tank head space and the ignition of solid or liquid waste stored in the tanks. Very low energy deposition levels are required to ignite flammable gas while relatively high deposition levels are required to ignite solid or liquid waste. This report identifies the appropriate target area of concern for both types. The results are as follows:

1. For flammable gas concerns, the assumed area should be the area of each tank farm including all tanks within the farm, resulting in a frequency of impacting any of the tanks as $2 \times 10^{-2} / \mathrm{yr}$ (i.e., once in 50 years a lightning strike on a farm could cause spark[s] in a tank[s] in that farm). The result is based on the highly conservative assumption that any strike within a farm could affect any or all the tanks. This does not consider the gas concentration in the head space, only that a spark could occur.

2. For solid and liquid wastes, the assumed area should be the tank's cross-sectional area, resulting in a frequency of any tank being affecting of $5 \times 10^{-3} / \mathrm{yr}$ (i.e., one of the tanks may have a strike above it every 200 years). This is based on the conservative assumptions that all tanks contain dry, fuel-rich waste and that a strike anywhere above the tank will result in a large energy deposition in the waste.

Given these probabilities and given a strike in the areas specified, it is appropriate to evaluate the likelihood that waste conditions will exist to support combustion; that sufficient energy will be deposited in the solid, liquid, or gaseous waste to ignite the waste; and the likelihood 
that any such ignition will lead to unacceptable results. The results are summarized as follow:

- Analysis and tank head space measurements indicate that the total time the tanks on most farms would exceed the Lower Flammability Limit is less than 8 hours per year $\left(10^{-3} / \mathrm{yr}\right)$. While monitoring and analysis continue and issues such as the likelihood that a storm will cause a gas release event from the waste have not yet been fully resolved, the evidence clearly supports the conclusion that the probability of a flammable gas mixture existing in a tank is low.

- Not all tanks contain dry, fuel-rich waste and where it exists in tanks, it may not be wide-spread. It appears that there may be organic concerns in about $20 \%-30 \%$ of the tanks. And in those tanks the organics may be wet enough to preclude ignition or may be localized within the tank. While characterization and analysis continue, the evidence supports the conclusion that, given a strike on a tank, the probability of lightning energy being in a dry, fuel-rich location is very conservatively assumed to be 1.0 in this report.

- It is not possible to determine the likelihood that sufficient energy will be deposited into the waste or gas to cause ignition. Experiments elsewhere and rocket-triggered tests demonstrate that energy from lightning strikes takes many paths. Those penetrations which are well grounded to the tank structure and those risers which do not have instrumentation are very unlikely to deposit energy in the waste. By including all paths (including those which do not communicate with the waste), the likelihood of energy deposition is conservatively assumed to be one.

- Many farms in general and most tanks in particular have a relatively target-free area above them, e.g., few pipes, ducts, risers. There other structures (light poles, fences, buildings) that may be more likely to send up streamers which connect to the stepped leader than tank risers. No credit for these other structures and the cross-sectional area of the largest tanks is assumed as the target area for lightning to affect organic waste. A factor or 2 to 10 is conservatively included by using the cross-sectional area of the tank as the target area.

- The ongoing accident analyses have assumed that ignition of flammable gas within the headspace of a tank will cause dome collapse with a very large release of radioactive and toxic material. Ongoing studies of tank dome structural integrity and the results of a recent Delphi panel review indicate that this is a very conservative assumption.

Because of the uncertainties in many aspects of the assessment of lightning risks, it is not possible to demonstrate quantitatively that an unacceptable lightning-caused event is incredible. The lightning strike probability indicates the possibility of a strike within the tank farms within the remaining life of the tanks. The qualitative factors that are known, however, support the conclusion that the likelihood of igniting the waste is low. Because of -- 
the uncertainty associated with this analysis, it is appropriate and necessary to take further steps to reduce this risk.

Potential actions have been assessed quantitatively where possible and qualitatively when necessary to identify the range of actions and benefits. On the basis of these results, Westinghouse Hanford Company had developed a recommended set of actions which it believes will provide an acceptable level of safety in a timely manner while characterization, studies, and analyses are ongoing. These actions include:

1. Take the necessary corrective actions of grounding $20 \%-30 \%$ of the risers that are not ${ }^{-\cdots}-$ now acceptable and bonding the instrumentation in $2 \%$ of the risers to meet lightning protection code requirements (NFPA 780);

2. Consider installation of grounded air terminals on existing power and light poles throughout the tank farms. Depending on the characteristics of the farm, this would. provide from $0 \%$ (some farms do not have light poles in places to provide protection) to $75 \%$ improvement in lightning protection.

Greater protection could be provided by the addition of more poles and grounded air terminals, the use of grounded metal cages, or a catenary system over appropriate farms. Under the best conditions, these systems do not provide a degree of protection greater than 99.5\%-99.9\%. These protection systems would impact ongoing tank operations and sampling, require a diversion of significant resources, and result in increase occupational exposure for the workers installing the systems. Westinghouse Hanford Company does not recommend the more elaborate protection systems, but rather the corrective actions identified above.

Continuing research, analysis, and discussion concerning the behavior of flammable gas, organic pools, and solid waste are expected to confirm the validity of this approach.

However, these results will be closely monitored to determine the need for additional action.

Because of the qualitative nature of much of the available information, others may judge the need for greater or lesser corrective actions. The purpose of this report is to provide the basis for such consideration. 
WHC-SD-WM-ES-387, Rev. 0

This page intentionally left blank. 


\section{CONTENTS}

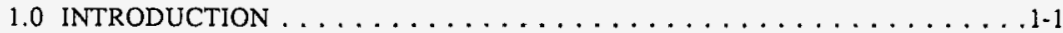

2.0 SITE CHARACTERISTICS WITH RESPECT TO LIGHTNING $\ldots \ldots \ldots \ldots . . .2-1$

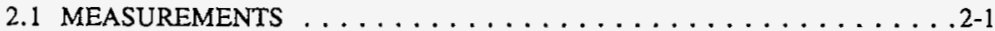

2.2 CALCULATIONS . . . . . . . . . . . . . . . . . .

2.3 IN-SITU REPORTED DATA $\ldots \ldots \ldots \ldots \ldots \ldots \ldots \ldots \ldots \ldots .5$

2.4 CONCLUSION . . . . . . . . . . . . . . . . . . . .

2.5 REFERENCES . . . . . . . . . . . . . . . . . 2-6

3.0 LIGHTTNING FLASH CHARACTERISTICS $\ldots \ldots \ldots \ldots \ldots \ldots \ldots$. . . . . . . .

3.1 GENERAL LIGHTNING CHARACTERISTICS $\ldots \ldots \ldots \ldots \ldots \ldots$. 1

3.2 LIGHTNING EFFECTS $\ldots \ldots \ldots \ldots \ldots \ldots \ldots \ldots \ldots \ldots . \ldots \ldots$

3.3 TYPICAL LIGHTNING PROTECTION $\ldots \ldots \ldots \ldots \ldots \ldots \ldots \ldots .2$

3.4 REFERENCES $\ldots \ldots \ldots \ldots \ldots \ldots \ldots \ldots \ldots \ldots \ldots \ldots . \ldots \ldots$

4.0 TANK CHARACTERISTICS WITH RESPECT TO LIGHTNING $\ldots \ldots \ldots \ldots$. . . .

4.1 POTENTIAL RESULTS OF LIGHTNING STRIKES $\ldots \ldots \ldots \ldots \ldots \ldots 4-1$

4.2 GENERAL TANK TARGET AREA $\ldots \ldots \ldots \ldots \ldots \ldots \ldots \ldots .4 .2$

4.3 TANK WASTE TARGET AREA $\ldots \ldots \ldots \ldots \ldots \ldots \ldots .4 .3$

4.4 MISCELLANEOUS OBJECTS WITHIN THE TANKS $\ldots \ldots \ldots \ldots \ldots 4-5$

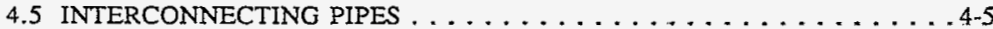

4.6 RISER GROUND CHARACTERISTICS $\ldots \ldots \ldots \ldots \ldots \ldots \ldots \ldots .4 .6 \ldots$

4.7 EQUIPMENT/RISER BONDING CHARACTERISTICS $\ldots \ldots \ldots \ldots \ldots 4-8$

4.8 TANK STRUCTURAL RESPONSE . . . . . . . . . . . . . 4-8

4.9 MITIGATION . . . . . . . . . . . . . . . . 4-12

4.10 CONCLUSIONS $\ldots \ldots \ldots \ldots \ldots \ldots \ldots \ldots \ldots \ldots \ldots \ldots \ldots \ldots \ldots \ldots \ldots \ldots .14$

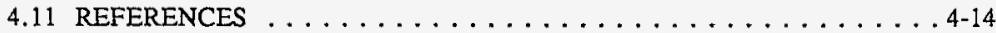

5.0 LIGHTNING-RELATED ATTRIBUTES OF TANK WASTE $\ldots \ldots \ldots \ldots \ldots$ 5-1

5.1 GRE AND WEATHER/WASTE OBSERVATIONS $\ldots \ldots \ldots \ldots \ldots$ 5-1

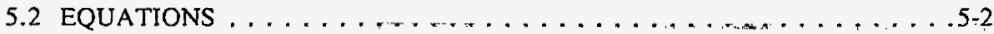

5.3 ORGANIC PHENOMENOLOGY $\ldots \ldots \ldots \ldots \ldots \ldots \ldots \ldots . \ldots \ldots$

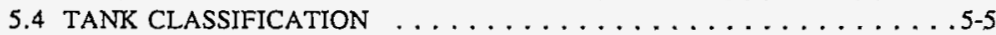

5.5 CONCLUSIONS . . . . . . . . . . . . . . . .5-5

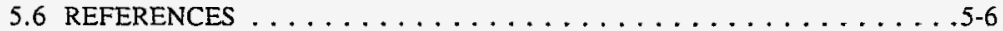

6.0 CONCLUSIONS/RECOMMENDATIONS $\ldots \ldots \ldots \ldots \ldots \ldots \ldots$. . . . . . . . 
WHC-SD-WM-ES-387, Rev. 0

\section{CONTENTS (continued)}

APPENDICES

A CODE APPLICABILITY $\ldots \ldots \ldots \ldots \ldots \ldots \ldots \ldots \ldots \ldots \ldots \ldots$

B LIGHTNING-RELATED OCCURRENCE REPORTS . . . . . . . . . . B-1

\section{LIST OF TABLES}

2-1 Bureau of Land Management Lightning Data . . . . . . . . . . . . 2-3

4-1 Riser Configuration with Respect to Lightning for A, BX, and T Farms . . . . 4-17 
WHC-SD-WM-ES-387, Rev. 0

\section{LIST OF TERMS}

BLM

GAI

Bureau of Land Management

GRE

HEPA

LFL

NLDN

Global Atmospherics, Inc.

Ground Ring Electrode

High Efficiency Particulate Air (filter)

Lower Flammability Limit

National Lightning Detection Network 
WHC-SD-WM-ES-387, Rev. 0

This page intentionally left blank. 


\section{PROBABUITY, CONSEQUENCES, AND MUTIGATION FOR LIGHTNING STRIKES TO HANFORD WASTE TANKS}

\subsection{INTRODUCTION}

The purpose of this paper is to evaluate the probability and potential consequences of lightning strikes affecting the underground waste storage tanks. The direct effects of the lightning are considered and not the radiological analysis resulting from an accident such as a waste fire or dome collapse. General recommendations are made to mitigate potential lightning strikes.

The safety of the waste stored in the large, underground tanks at Hanford is a concern of the Department of Energy. This waste was generated as part of the reprocessing of irradiated fuel from the reactors on the Hanford site to recover the plutonium for the Department of Defense from 1944 until the mid-1980s. Tens of millions of gallons of waste are stored in the 177 tanks that range in capacity from $190,000 \mathrm{~L}(50,000 \mathrm{gal})$ to over $3,800,000 \mathrm{~L}$ (1,000,000 gal).

The potential hazard is that certain types of waste chemical composition (which varies among the tanks) may be susceptible to ignition. For combustion to initiate, three components are necessary: fuel, oxidizer, and ignition source. Wastes having concerns as possible fuels are those which generate flammable gases and those which contain organic complexants and extractants. Waste tanks have a headspace with air and sludge with sodium nitrates/nitrites, so an oxidizer can always be assumed to be present. Finally for the waste to burn, there has to be a credible source of ignition.

It is generally recognized and demonstrated in this report that a lightning strike in a tank farm is an infrequent event. As such, the events of concern are those that can potentially have significant offsite consequences. For purposes of this report, unacceptable consequences are those which cause a significant release of radioactive or toxic materials.

For flammable gases the ignition source can have very low energy. The potential consequences of concern are related to dome collapse. In order to assess this hazard, the probability of lightning striking in a manner to cause a spark is analyzed and the likelihood of the concurrent existence of a flammable gas mixture is also assessed. But there is presently a lack of definitive data to assess how often headspace gas concentrations actually exceed the Lower Flammability Limit.

Organic complexants and extractants exist in some of the tanks 100 percent of the time. Controls can be provided to reduce the likelihood of man-made sources of ignition. The only credible naturally-occurring ignition source that can produce enough energy to ignite a waste fire is lightring. Lightning has the potential to ignite the solid and liquid wastes if a 
significant arc between the waste surface and an object (e.g., a riser or equipment in a riser) occurs or significant energy is deposited in the waste in the form of ohmic heating. As with the flammable gas issue, the lack of definitive tank content data and clear rules for waste susceptibility preclude stating that ignition of organic waste is incredible.

The ultimate question is whether lightning can initiate an accident with unacceptable consequences. For purposes of this report unacceptable consequences are those which cause a significant release of radioactive or toxic material. A pressure transient from an organic fire or a smail flammable gas burn which causes a High Efficiency Particulate Air (HEPA) filter to rupture would not result in a significant release in this context. However, a dome collapse would result in a significant release of radioactive or toxic material.

While there is quite a bit of conservatism in the existing evaluations, neither a flammable gas nor organic waste ignition can be categorically demonstrated as incredible. Therefore a practical mitigation proposal is made.

Chapter 2.0 of this report describes the site with respect to lightning strike frequency and intensity. Chapter 3.0 gives the characteristics of lightning in general. Chapter 4.0 explains the tank structural issue, the riser configuration, and how they are grounded. It also includes the results of the field walkdowns for grounding adequacy and the recommendations for mitigation. Chapter 5.0 explains the contents of the tanks and their vulnerability to energy deposition from a lightning strike to the ground above a tank, one of its risers, or the equipment associated with the risers. Chapter 6.0 presents the conclusions and recommendations. 


\subsection{SITE CHARACTERISTICS WITH RESPECT TO LIGHTNING}

The Hanford Site is located in southeastern Washington and experiences about ten thunderstorm days per year with a range of between three and 23 (Hoitink and Burk 1994). A day is counted as a thunderstorm day when a trained observer hears thunder. The thunder may be from only one lightning flash or maybe from hours of storms containing hundreds of such flashes. There are three approaches to determine the frequency of lightning strikes: measurements, calculations, and in-situ reports. This section assesses the state of knowledge for all three approaches to determine the appropriate strike frequency.

\subsection{MEASUREMENTS}

Global Atmospherics, Inc., (GAI) operates the National Lightning Detection Network ${ }^{\mathrm{TM}}$ (NLDN) and is based in Tucson, Arizona. The company is a private enterprise which provides information to the National Weather Service and to other government agencies and private businesses. GAI uses over 100 ground-based sensors throughout the United States to detect and locate (through triangulation) ground lightning strikes. At present GAI is able to locate a ground strike within about 300 meters with a detection efficiency of about $80 \%$ $90 \%$. GAI reported that over a five year period (January 1, 1991, through January 1, 1996) there were about 600 lightning strikes in the 2106 square kilometer (a rectangle about 54 by $39 \mathrm{~km}$ ) area centered around the tank farms in 200 East and 200 West. This yields a probability of less than 0.06 per kilometer ${ }^{2}$ (using 600 strikes for the area over five years). There is some variability across the area in the frequency of strikes as one might expect considering the geography of the area. The Rattlesnake Hill area, 20-30 km to the south and west of the site, has a larger percentage of the strikes than the rest of the area. One $9 \mathrm{~km}^{2}$ area in that area had more that $0.30 \mathrm{strike} / \mathrm{km}^{2} / \mathrm{yr}$, while the frequency was 0.015 strike $/ \mathrm{km}^{2} / \mathrm{yr}$ directly over 200 East and 200 West. The high frequency is probably due to an orographic effect in which the hills "lift" the air, creating better conditions for lightning than if the hills did not exist. If one eliminates the Rattlesnake Hill area from inclusion in the Hanford area data, the five years of data from a smaller area surrounding and including the tank farms and the ten years of data from the Bureau of Land Management (BLM) discussed below show a consistent value of $0.045 \mathrm{fl} / \mathrm{km}^{2} / \mathrm{yr}$ as a value for measured ground strikes. The limited amount of data (10 BLM points) did not lend itself to a sophisticated mathematical distribution to determine confidence level.

The Bureau of Land Management stated that the system may not detect essentially coincidental flashes and a strike extremely close to a sensor can "saturate" the sensor for a few seconds. During violent weather, there may be more than 1 channel from the cloud to the ground. For example, in Florida there is an average of 1.3 channels to ground that may be kilometers apart. Lightning detection systems could not differentiate the existence of a second channel until recently. Small flashes and those with non-standard waveshapes will not be detected. Global Atmospherics, Inc., states the efficiency of detection for the nationa] system was 70 percent in $1989-1991,65$ to 80 percent in 1992 to 1994 , and 80 to 90 percent 
in 1995. The BLM did not quote a detection efficiency although it is assumed to be no better than GAI's. The BLM detection technology is basically the same as GAI's while the communications link is land-based as opposed to the satellite system of Global Atmospherics, Inc. For purpose of this report, a detection efficiency of 75 percent will be assumed.

Hanford-area thunderstorms do not generate very many flashes. There were about 120 flashes per year reported by Global Atmospherics, Inc. The Bureau of Land Management reported about 50 per year over a smaller land area than GAI reported. The BLM area may not cover the entire area observed to experience 10 thunderstorm days each year, while the GAI area is larger than the area the weather observers at Hanford can realistically hear every thunderclap. There is an average of 10 thunderstorm days per year and between 50 and 100 detected ground flashes each year. If each thunderstorm day is the result of one thunderstorm, the result is that a "typical" thunderstorm in the Hanford area may generate 5-10 detected cloud-to-ground flashes.

The Pacific Northwest is not a high lightning storm area in general because of the relatively cold temperatures in the ocean coastal waters. Ocean storms do develop lightning as they progress east.

Global Atmospherics, Inc., also reported the distribution of the strikes as a function of the months. July has the most lightning strikes of any month, with most strikes annually occurring between May and August. However, in February 1994 there were about 15 to 20 strikes over the Hanford area illustrating the occurrence of a thunderstorm or two in that month, which is unusual. The flash data are consistent with reportable occurrences noted in Appendix B. This information can be used to decide optimum times to do certain evolutions in the tank farms which may place the tanks at a higher risk with respect to lightning events.

Finally, Global Atmospherics, Inc., characterized the peak current of the lightning strikes. The peak current for the average positive polarity flash was about 30,000 amps, while none of the 600 ground flashes exceeded 83,000 amps over the five year period. About 10 percent of the flashes had positive polarity. The average negative polarity flash had a peak current of about 17,500 amps with a few scattered above 60,000 amps. None exceeded 100,000 amps. GAI states the system measures within 30 percent RMS for lightning current based on measurements of triggered lightning subsequent strokes. If further testing of tank characteristics (such as RF testing) is done to determine lightning current splitting in the tank, the measured lightning currents may be useful.

Information was collected from the Bureau of Land Management (BLM) with respect to lightning strike frequency. Their data (as summarized in Table 2-1) cover from 1986 through 1995. BLM was responsible for operating the developing technology within their charter to manage federal forests, including identifying potential forest fire locations. BLM operates a system in Western United States using the same technology (including sensors) as Global Atmospherics, Inc., but with a less sophisticated algorithm for locating the strike precisely. 
Table 2-1. Bureau of Land Management Lightning Data.

\begin{tabular}{|c|c|c|c|}
\hline Year & Number of flashes & Negative fashes & Positive flashes \\
\hline 1986 & 66 & 61 & 2 \\
\hline 1987 & 9 & 8 & 1 \\
\hline 1988 & 28 & 16 & 11 \\
\hline 1989 & 54 & 46 & 8 \\
\hline 1990 & 60 & 55 & 5 \\
\hline 1991 & 80 & 67 & 9 \\
\hline 1992 & 88 & 76 & 5 \\
\hline 1993 & 46 & 41 & 1 \\
\hline 1994 & 41 & 38 & 0 \\
\hline 1995 & 22 & 13 & 8 \\
\hline Total & 494 & 421 & 50 \\
\hline
\end{tabular}

Note:

The number of flashes is as calculated by the BLM. The negative and positive flashes were manually counted from the plots. The graphics presenting the information are such that a "-" (for a negative flash) could be masked by the longitude and latitude numerals or " + " used to reference points on the maps. The sum of the "negative flashes" and the "positive flashes" may not equal the "number of flashes" because of the manual counting process.

BLM information is for a rectangle of $36 \mathrm{~km}$ by $28 \mathrm{~km}$ or $1008 \mathrm{~km}^{2}$. Because the area covered is smaller (48 percent) than the Global Atmospherics, Inc., data, it excludes part of the Rattlesnake Ridge. The BLM overall flash frequency is $0.045 \mathrm{fl} / \mathrm{km}^{2} / \mathrm{yr}$ compared to the GAI frequency of $0.06 \mathrm{fl} / \mathrm{km}^{2} / \mathrm{yr}$. Over the five years of common data (1991 to 1995) the ratio of positive to negative flashes is about the same (1:9) for the two data sets. The ten years of data from BLM would suggest the last five years were not atypical with respect to lightning strikes in the $200 \mathrm{E}$ and $200 \mathrm{~W}$ area, at least when one considers twice as long a time period.

The Hanford Meteorology Office was contacted with respect to thunderstorm days over the past ten years. The results are: 1986-9 T-days in the area, 1987-7 T-days, 1988-4 T-days, 1989-10 T-days, $1990-11$ T-days, $1991-12$ T-days, $1992-7$ T-days, $1993-13$ T-days, 1994-10 T-days, 1995-9 T-days. This average of greater than $9 \mathrm{~T}$-days per year is consistent with the ten thunderstormdays per year assumed in the calculational techniques and supports the 
conclusion that the measured data are not skewed by unusual weather conditions over the time period.

As noted earlier, thunderstorm days are based upon human observation. The Hanford weather observatory is located just east of the $200 \mathrm{~W}$ area. Because it is in the center of a large bowl formed by the surrounding ridges, the Hanford observatory may detect thunder at a greater range than the "typical" observer located at an airport or other urban or suburban location. The site's flora (no woods, comfields, etc.) and few man-made structures also facilitate the sound of thunder travelling farther than in many other locations where there are weather observers.

\subsection{CALCULATIONS}

The following discussion is included in this report for the sake of completeness. Over the years there have been many attempts to fit equations to lightning strike frequency. The various fits resulted in a wide range of predictions as one can see below. Included in the equations in some cases was a dependency upon latitude. Recent measurements do not support the dependency. While these calculational techniques are of interest, it is more appropriate to use actual data if sufficient, credible information exists.

The number of annual cloud-to-ground lightning discharges is a function of the number of thunderstorms an area has in a given year. The calculations below are based on an average area with a mix of convective and frontal storms. Hasbrouck (1995) presents two equations for ground-flash density. The latitude dependency in the equations has recently been found to not be supported by measurements. Cowley and Stepnewski (1994) used a third equation, similar to the first two.

$$
F_{g}=0.1 \times\left(1+\{1 \mathrm{at} / 30\}^{2}\right) \times\left(0.02 \times \mathrm{T}_{\mathrm{d}}{ }^{1.7}\right)
$$

lat $=$ latitude of the site in degrees \{for Hanford, $47^{\circ}$ \}

$\mathrm{T}_{\mathrm{d}}=$ Thunder day/yr (from isokeraunic map) \{for Hanford, 10 \}

$$
F_{z}=0.1 \times\left(1+\{\text { lat } / 30\}^{2}\right) \times F_{t} \times T_{d}
$$

$F_{t}=$ Total Daily Flash Density $\left(\mathrm{fl} / \mathrm{km}^{2} / \mathrm{T}_{\mathrm{d}}\right)$

0.4 to 1.1 [based upon: $3 \mathrm{fl} / \mathrm{min}, 1-3$ hour $/ \mathrm{storm} / \mathrm{T}_{d}, 500 \mathrm{~km} / \mathrm{storm}$ ]

$$
\mathrm{Fg}=0.1 \times \mathrm{T}_{\mathrm{d}}
$$

Equation 2-1 gives a ground-flash density for the Hanford area of 0.3. Equation 2-2 gives a range of 1.4 to 3.8 based on assumed storm duration. Using equation $2-3$, one calculates $1.0 \mathrm{ground}-\mathrm{flash} / \mathrm{km}^{2} / \mathrm{yr}$. 


\subsection{N-SITU REPORTED DATA}

There has been no formal employee reporting system for cloud-ground flashes at Hanford. Cowley and Stepnewski (1994) report that, "Actual lightning strikes in the tank farms have not been documented. However, conversations with tank farm operations personnel indicate that lightning strikes do occur within the tank farms. This gives credence to the idea that strikes occur within tank farms about once a year." Some of the anecdotal evidence has to do with the loss of instrumentation during a storm. Loss of instrumentation is usually indicative of a power perturbation and does not indicate a direct threat to the waste. (Note for example the descriptions of RI-WHC-SOLIDWASTE-1991-1002 and RL-WHCANNALLAB-1991-1005 in Appendix B. In each case a power perturbation caused the loss of instruments/ventilation.) It is unknown how much is hearsay as opposed to personal experience. If the actual flash frequency is $0.06 \mathrm{fl} / \mathrm{km}^{2} / \mathrm{yr}^{2}$ and the area of all the farms (including both the DST and SST tank farms) is about $0.4 \mathrm{~km}^{2}$, then one would expect a flash actually within some tank farm to have a frequency of 0.024 per year or an occurrence about once every 40 years, significantly less than the once per year or several years anecdotally noted.

A second source of information is Kelly and Hasbrouck (1995). They note that Hanford had the highest number of reports of "lightning occurrences"/ thunderstorm/year of any of the DOE sites. "Lightning occurrences" in this context are any reportable occurrences in which the word "lightning" was in the text. In fact, the ratio was twice as high as the next site (Savannah River). There were about 7 valid reports for each year compared to about 15 for Savannah River (who has five times as many thunderdays each year) and about four for Oak Ridge (who also has about five times as many thunderdays each year compared to Hanford). Site characteristics probably significantly influence this information. A single passing storm cell has more opportunity to affect a larger area, such as Hanford, than a smaller area, such as Oak Ridge. It is assumed that the basic reporting requirements are similar for each site, although this has not been investigated for this report. Appendix B presents a review of 33 occurrence reports associated with lightning from 1990 through 1995 . It points out that there were three cases in which a single lightning flash likely resulted in multiple lightning occurrences ( 13 of the 16 reports associated with $200 \mathrm{E}$ and $200 \mathrm{~W}$ were probably related to these three flashes.)

The reported information confirms that fact that a lightning strike may occur is the tens of square kilometers surrounding and including the $200 \mathrm{E}$ and $200 \mathrm{~W}$ areas, including tank farms, about once per year. Equipment is most often affected through the electrical distribution system. Loss of an instrument neither means that it was directly struck by lightning nor can it directly cause combustion. No documented reports or evidence of lightning striking a tank farm exist. 


\subsection{CONCLUSION}

A ground flash frequency of $0.06 / \mathrm{km}^{2} / \mathrm{yr}$ can be assumed. This is arrived at by dividing the measured values $\left(0.045 \mathrm{fl} / \mathrm{km}^{2} / \mathrm{yr}\right)$ by the detection efficiency $(75$ percent). The frequency is conservative in that it includes some areas that experience more lightning strikes on the average than the tank farm areas. If one wants to add additional conservatism for multiple ground strokes affecting divergent targets, one could assume $0.1 \mathrm{fl} / \mathrm{km}^{2} / \mathrm{yr}$. This is more than 1 order of magnitude less than originally assumed by Cowley and Stepnewski (1994) for frequency.

\subsection{REFERENCES}

Cowley, W. L., D. D. Stepnewski, 1994, Evaluation of Hazards from Lightning Strikes to Tank Farm Facilities, WHC-SD-WM-SARR-027, Revision 0, Westinghouse Hanford Company, Richland, Washington.

Hasbrouck, R. T., 1995, Two Methods for Deternining the Probability of Lightning Striking a Facility, FSIG-95-05-10-01, Lawrence Livermore National Laboratory, Livermore, California.

Hoitink, D. J., K. W. Burk, 1994, Climatological Data Summary 1993 with Historical Data, PNL-9809/UC-603, Pacific Northwest Laboratory, Richland, Washington.

Kelly, M. V., and R. T. Hasbrouck, 1995, Lightning-Related Occurrences at DOE Facilities, FSIG-95-12-09-1, Lawrence Livermore National Laboratory, Livermore, California. 


\subsection{LIGHTNING FLASH CHARACTERISTICS}

\subsection{GENERAL LIGHTNING CHARACTERISTICS}

Lightning can be caused by thunderstorms, snow storms, volcanos, and dust storms. Hanford is too distant from any active volcano to have lightning caused by volcanic activity. Dust storm lightning is relatively rare and does not have currents as high as thunderstorm lightning.

To understand the hazard lightning presents, it is necessary to understand the characteristics of lightning. Of the several types of lightning that are produced in a thunderstorm (e.g., intracloud, cloud-to-ionosphere, intercloud, cloud-to-air, and cloud-to-ground $\{C-G\}$ ), the only one of concem to the safety of the waste in the storage tanks is C-G. Hasbrouck and Majumdar (1995) report that a typical flash lasts approximately one-half to one second. The severity of a lightning strike is normally measured by the magnitude of the peak current, charge transfer, and action integral. Based on data collected over decades around the world, for negative lightning 200,000 amps is generally accepted as the $99^{\text {th }}$ percentile value. In other words, 99 percent of $C-G$ negative lightning flashes have less than 200,000 amps. As noted in Chapter 2.0, data collected using indirect measurements over the past five years for the Hanford area indicate that, of the $600 \mathrm{C}-\mathrm{G}$ flashes, no negative lightning flashes exceeded 100,000 amperes with a $30 \%$ measurement accuracy.

Hasbrouck (1989) describes the phenomenology of a lightning strike. A "stepped leader" or ionized channel moves toward the earth in increments of about $50 \mathrm{~m}$. The current may peak at -1000 amps while the average may be about -100 amps. These steps take about one microsecond and are separated by a 50-microsecond pause. Positively charged streamers start moving up from the earth particularly from tall, grounded, pointed objects. One or more streamers may be formed. As the distance between the stepped leader and streamers narrows, breakdown of the intervening gap will occur when the field is greater than the dielectric strength of the air. This "striking distance" is normally in the range of 30 to 100 meters.

The positive "return stroke" seeks to neutralize the ionized channel's negative charge following the channel at 35 to $100 \mathrm{~m} / \mathrm{microsecond} \mathrm{to} \mathrm{its} \mathrm{upper} \mathrm{end.} \mathrm{It} \mathrm{is} \mathrm{possible} \mathrm{that} \mathrm{in} \mathrm{a}$ single flash, more than one streamer may be involved with one or more return strokes. The potential breakdown may occur across parallel paths. There may be $2-3$ ground strike points separated by up to 10 meters. Or there may be a cluster of several points within a few $\mathrm{cm}$ partly dependent upon the geometry (e.g., a flat roof or a pointed air terminai).

As the potential of $50,000,000$ to $100,000,000$ volts approaches earth, it makes the final jump to a streamer, determining the location of the strike and the magnitude of the return current. Typically one considers the "cone of protection" of a structure as the area bounded by a circle with a radius of the height of the structure. The "cone of protection" for more energetic strokes $(200,000$ amperes) is more effective than for the less severe strokes $(50,000$ 
amperes) because the former have a greater striking distance than the latter. This is because the more energetic stepped leader can seek a streamer from a more distant, taller, more conductive structure than the less energetic flash.

The current for the return stroke will flow through parallel paths to the point of connection(s) between the stepped leader and one or more streamers.

\subsection{LIGHTNING EFFECTS}

The effects of a lightning flash can be either direct or indirect. Physical damage to a structure is direct effect and occurs when the return-stroke current flows through material which is relatively non-conductive and significant ohmic heating occurs or arcing occurs. The current may be contained within the concrete wall of a tank using reinforcing bar as the conductor. Where gaps exist, arcing may occur vaporizing moisture in the concrete. Arcing may occur in the tank between the metal tank walls and the waste, between the tank dome reinforcing bar and a riser that is not well bonded electrically to the rebar, between equipment passing through the riser and the riser, between equipment passing through a riser and the waste surface, including low energy sparks that could ignite flammable gas.

Indirect effects of a lightning flash are electrical interference and fires that result from arcs. The energy from a flash may melt metal items in a tank which could fall into the waste. If the item were large enough and hot enough (i.e., it contained a significant amount of energy), certain types of waste may be ignited.

Lightning is unpredictable in its path and tremendous in its effects. It is the leading weather-related cause of injuries and deaths in the United States. The American Petroleum Institute states, "Even when all known precautions are employed, prevention or safe dissipation of direct-strike lightning cannot be absolutely assured... The methods provided in this section have been successful except on the rare occasions when lightning acted in an unpredictable fashion...Prevention of direct-stroke lightning is generally impossible." (API 1991)

As discussed in Chapter 4.0, it is accepted that a lightning strike in the vicinity of a tank(s) on a farm will lead to an electrical current in the concrete. Also discussed at length in Chapter 4.0 is the fact that the underground storage tanks will act as electrodes with respect to electricity, including lightning.

\subsection{TYPICAL LIGHTNING PROTECTION}

IEEE Std 142 (1991) states, "Lightning cannot be prevented; it can only be intercepted or diverted to a path which will, if well designed and constructed, not result in damage. Even this is not positive, providing only 99.5-99.9 percent protection." At the 99.5 percent protection level, the probability of a strike on the area of a farm with an area of $0.04 \mathrm{~km}^{2}$ 
would change from $0.002 \mathrm{fl} / \mathrm{yr}$ or one strike in 500 years to $0.00001 \mathrm{fl} / \mathrm{yr}$ or one strike in 100,000 years.

Typical lightning protection takes one of two forms: structure design or air terminal (lightning rod/tower or overhead ground wires). For example the appropriate grounding of a steel tank provides protection through the structural design. A lightning rod on a barn or light pole is one example of an air terminal. Wires above high voltage lines and a catenary design are examples of overhead ground wires. The goal is to guide the lightning current to ground without adversely passing through something that could be affected (like a person, house, weapons bunker, tank waste). NFPA 780 provides "...lightning protection system installation requirements for:...(e) structures containing flammable vapors, flammable gases; - or liquids that can give off flammable vapors." (NFPA 780 1995)

Lightning protection does present an attractive target for lightning since it is designed to intercept lightning. Therefore any installed system (for example in the tank farms) does present the possibility that a lightning strike may occur at that location (in the tank farms) which otherwise would have struck outside the area. If the lightning protection ground system does not successfully divert the current outside the farm, it is possible that a small spark could occur in a tank with flammable creating ignition. The "footprint" of the farm is expanded slightly. Since lightning is so infrequent and there has been no evidence that lightning has been attracted to the existing targets (light poles, fences, radiation monitoring poles, etc.) within the farms, the argument that any mitigation will adversely affect the farms is not persuasive.

\subsection{REFERENCES}

API, 1991, Protection Against Ignitions Arising Out of Static, Lightming, and Stray Currents, Recommended Practice 2003, Fifth Edition, American Petroleum Institute, Washington, D.C.

IEEE Std 142, 1991, IEEE Recommended Practice for Grounding of Industrial and Commercial Power Systems, Institute of Electrical and Electronics Engineers, Inc., New York, New York.

Hasbrouck, R.T., 1989, Lightning - Understanding It and Protection From Its Effects, National Lightning Safety Institute, Louisville, Colorado.

Hasbrouck, R.T., K.C. Majumdar, 1995, Development of a Guidance Document for Lightning Protection of DOE Facilities, UCRL-JC-119983, Lawrence Livermore Laboratory, Livermore, California.

NFPA, 1995, Standard for the Installation of Lightning Protection Systems, NFPA 780, 1995

Edition, National Fire Protection Association, Quincy, Massachusetts. 
WHC-SD-WM-ES-387, Rev. 0

This page intentionally left blank. 


\subsection{TANK CHARACTERISTICS WITH RESPECT TO LIGHTNING}

For a lightning strike to have the potential of igniting tank waste, it must somehow pass through the waste or heat a part of the tank that is in contact with the waste. The various paths that lightning may take to affect the waste are discussed below. The tank structure is a second concern and is discussed at length below in Section 4.8. The electrical current will choose the paths of least impedance. Besides the tanks and risers there are wooden light poles on most farms, chain link fences surrounding most farms that are periodically grounded, some power poles, and other metallic protrubances. The fence and poles are likely sources for upward streamers.

Since the tanks are buried under 1.8 to $2.1 \mathrm{~m} \mathrm{(6ft} \mathrm{to} 8 \mathrm{ft}$ ) of overburden, a ground strike is less likely to result in significant current entering inside the tank to the waste since the current will form fulgurites in the highly resistive soil and the concrete shells of the underground tanks which, as discussed below, may act as ground electrodes. For solid/liquid ignition, the question then becomes what targets exist for lightning to strike such that energy can penetrate a tank to affect the contents.

Since the Double-Shell Tanks (DSTs) are completely enclosed containers, their vulnerabilities to lightning effects are significantly less than SSTs. Uman notes in Cowley and Stepnewski (1994), "The metal double-wall tanks provide effective lightning protection...if all tank apertures and penetrations can be properly protected from current and electromagnetic field entry. The tanks, being buried and having large surface area (concrete over metal), are inherently grounded." Since the metallic dome risers are reportedly welded to the metal tank roof, there is not the concern that the riser is not electrically bonded to the tank.

For simplicity of discussion in this section, unless otherwise noted, the word "riser" will include all penetrations into a tank which may be a lightning target including: the riser proper; equipment in the riser such as instruments, ventilation, pumps, etc., and interconnecting underground piping with associated valves. There may also be a target somewhat remote from the riser proper, such as an instrument cabinet with a conduit containing wires attached to a riser. Depending on the electrical characteristics of the connections, such as resistivity, inductance, capacitance, and current-carrying capacity, a remote "target" could receive a strike that could affect a tank.

\subsection{POTENTIAL RESULTS OF LIGHTNING STRIKES}

To assure that all the potential accidents related to lightning and the underground storage tanks are addressed, a review of Buck (1993) was done.

Buck (1993) identified farm-specific and tank-specific potential lightning strike events as listed in Cowley and Stepnewski (1994). Table 1 (Cowley and Stepnewski 1994) lists 33 events which could be initiated by a lightning strike on a farm ranging from loss of 
instrumentation to ignition internal to a tank to portable compressor fire. Table 2 (Cowley and Stepnewski 1994) lists 48 tank-specific events if lightning were to strike the ground, a riser, an open pit, a closed pit, or other tank component. Since this report is concerned with only those events which lead to a significant release of radioactive or toxic material, the events associated with loss of instruments and fires external to the tanks are not considered further here. There are twelve identified sequences that lead to a short term "loss of confinement" (e.g., powered ventilation system shutdown). These events are not peculiar to lightning initiation and, without a spark/ignition in the tank, are not serious in that there would be no motive force to move a plume several hundred feet into the atmosphere such that it could then be dispersed to distant workers or offsite.

Of the 24 events which have a hazard of "spark or ignition source internal to the tank, " five are associated with the installation or removal of equipment (including crane usage), which activities are controlled to preclude the event. The control of these activities is not included in the scope of this report. If a pit is open there are five events in which a lightning strike. may cause a spark or ignition of material in the pit and the secondary effect is burning material falling into the vapor space. There are three events in which lightning is postulated to cause ignition of combustible material which is hypothesized to have been left in a closed pit and the ignited material enters the vapor space. There are two events (pump or leak detection control panel and heat trace panel) similar to the pit concerns, in which a lightning strike leads to flaming material, including sparks, falling through an open riser. The nine remaining events are associated with specific risers (passive ventilation, active ventilation, flake box, camera, FIC, thermocouple tree, another passive ventilation, Level Observation Well, solids level detector). These risers have been evaluated for grounding by Kiewert (1996).

Buck's review (1993) of potential events affecting the waste is inclusive. Analysis of the list of events indicates the scope of significant lightning-initiated events is limited to those discussed in this report. These events are riser-specific for events which may affect solid or liquid waste, such as ignition of flammable material which falls into the tank or sparks or specific risers being struck. This review allows one to proceed to the next step of determining the paths for lightning to affect the tank.

\subsection{GENERAL TANK TARGET AREA}

One of the more difficult issues with respect to tank vulnerability to lightning is the question as to how large an area is the applicable target area for a tank. That is, a strike in what area will affect the tank. Before determining that, one needs to consider what is meant by "affect" because there are several effects a tank and its waste can experience.

On the one hand, one could consider the whole tank farm as a lightning target. In some cases this is appropriate since there are interconnections of equipment scattered throughout the farm and the tanks. One can consider that the tanks are tied together electrically underground through interconnecting pipes and the cathodic protection system. As discussed 
below in "Tank Structural Response," the concrete has less resistivity than the backfill around the tanks. One way to consider the tanks is as twelve, huge, concrete-encased electrodes (for a farm with twelve tanks).

The farms take various geometries but in general are rectangles $120 \mathrm{~m}(400 \mathrm{ft}$ ) by $180 \mathrm{~m}$ ( $600 \mathrm{ft}$ ), such that the area is about $0.02 \mathrm{~km}^{2}$ per farm or less than $0.25 \mathrm{~km}^{2}$ for the twelve SST farms. (Including the DST farms would increase the area to $0.40 \mathrm{~km}^{2}$.) This approach of using farm area as the target is appropriate for consideration of structural effects because all tanks can be somewhat affected by a single flash through the interconnections. It is also used in the consideration of flammable gas because of the low energy threshold required for ignition of flammable gas and the possiblilty of a small spark being generated in a tank from a strike on equipment even indirectly connected to the tank.

\subsection{TANK WASTE TARGET AREA}

For sufficient energy to be deposited in liquid or solid waste to cause ignition, the strike must affect specific equipment that is not well bonded to the riser. In this case the tank farm area is not a concern, because the lightning energy does not have a path to the waste. The division of lightning current paths in the riser and the tank will depend on the relative resistance and inductance between the poorly bonded equipment and riser and the resistance and inductance through the equipment through the waste and into the metal tank wall.

A tank's cross-sectional area can be considered as the strike target area. A tank with a diameter of $24.4 \mathrm{~m}(80 \mathrm{ft})$ has an area of $465 \mathrm{~m}^{2}\left(5026 \mathrm{ft}^{2}\right)$ or approximately $5 \times 10^{-4} \mathrm{~km}^{2}$. If there is $1 \mathrm{fl} / \mathrm{km}^{2} / \mathrm{yr}$ as assumed in Cowley and Stepnewski (1994), then the probability that the cross-sectional area of a tank will be struck is $5 \times 10^{-4} / \mathrm{yr}$. This approach would suggest that the chances of energy travelling through the overburden to a riser, being carried on pipes or conduits to a riser, or going down to the tank and circulating through the tank to a riser could result in enough energy reaching the waste as to be a threat.

A detailed review of riser configuration on the tanks determined that the ground surface above many tanks is relatively free of pipes and conduits, particularly the SST farms. As discussed in Section 4.5, the interconnecting pipes are not likely paths to the waste. As part of WHC-SD-WM-TP-433, Single Shell Tank Riser Resistance to Ground Test Plan (Kiewert 1996), an inventory of riser size (both cross-sectional area and height) was done. For example, each of the twelve 1,850,000 L (500,000 gal) tanks in T Farm and four smaller tanks has from three to eleven risers. By using the riser radius and the height (high, conductive structures are more attractive to lightning than no structure), one can calculate an equivalent target area, TA, for each riser in $\mathrm{m}^{2}$.

$$
\mathrm{TA}=3.14159 \times(\mathrm{r}+\mathrm{h})^{2}
$$

where $r=$ radius of the riser in $m$, and $h=$ height of the riser in $m$. Or $r$ and $h$ may be expressed in inches and the multiplication factor is $0.002\left(3.14159 \times\{0.0254 \mathrm{~m} / \mathrm{in}\}^{2}\right)$. 
This does not consider the shadowing effect of a tall riser next to a low riser. Nor does it take into account the conduit to pump control station or ENRAF unistrut or instrument cabinet, nor those structures themselves.

Among the six A-Tank farm tanks, A-105 was by far the tank with the largest target area $\left(91.0 \mathrm{~m}^{2}\right)$ because of the several relatively tall risers it has. Even including $A-105$, the average area for the six A-Tanks was less than $40 \mathrm{~m}^{2}$.

The BX Farm target areas were influenced by tall risers for breather units. For example, $\mathrm{BX}-104(\mathrm{R}-1)$ and $\mathrm{BX}-106(\mathrm{R}-2)$ are the tallest structures on the three farms in Table 4-1. While these were the tallest risers at $2.4 \mathrm{~m}$ and $2.7 \mathrm{~m}(8 \mathrm{ft}$ and $9 \mathrm{ft})$ respectively, the breather risers for the other BX tanks were between $1.5 \mathrm{~m}$ and $1.8 \mathrm{~m}(5 \mathrm{ft}$ and $6 \mathrm{ft}$ ). Including BX-106 with its area of $47 \mathrm{~m}^{2}$ because of the breather and instrument risers, the average area of the 12 tanks is $31.2 \mathrm{~m}^{2}$.

For the $T$ tanks the ones with the largest target areas were $\mathrm{T}-203\left(33.5 \mathrm{~m}^{2}\right)$, $\mathrm{T}-107(33.4$ $\left.\mathrm{m}^{2}\right), \mathrm{T}-106\left(32.8 \mathrm{~m}^{2}\right)$, and T-112 $\left(31.5 \mathrm{~m}^{2}\right)$. T-102 has the smallest area with $12.8 \mathrm{~m}^{2}$. So for $T$ Farm the target area for each tank is less than $40 \mathrm{~m}^{2}$, at least less than 0.1 of the tank's cross-sectional area.

Table 4-1 provides the detailed information, tank-by-tank, riser-by-riser, for the A-Tank, the BX-Tank, and the T-Tank farms. If one were to assume that each of the 34 tanks had a target area of $500 \mathrm{~m}^{2}$, the area for the tanks on the three farms would be $17000 \mathrm{~m}^{2}$. The detailed riser-by-riser review calculates a total area of less than $1100 \mathrm{~m}^{2}$, or $1 / 15$ of the previous value for the 34 tanks.

Having identified the riser target area for an A Farm or a BX Farm or a T Farm tank as 50 $\mathrm{m}^{2}$, further evaluation of specific risers can be made. Particular attention is paid to risers that contain equipment that reaches or penetrates the waste surface. Thermocouple trees and level detectors are normally among the tallest targets (nominally $1.9 \mathrm{~m}$ [75 in.] or less) on tanks in the A, BX, and T Farms. This results in a target of $12.1 \mathrm{~m}^{2}$ of less for each of those risers. This area is included in the tank Target Area.

Other risers may be observation ports, breather pipes, spares, etc. These (as well as those identified above as having equipment which reach the waste) are of concern for two reasons. Could lightning strike current enter the riser and either cause a spark in a flammable gas mixture in the dome head space or pass into the rebar and cause damage? The structural effects on the concrete and rebar are discussed in 4.8 below. The potential for significant flammable gas ignition is coveredby the assumption of the whole tank farm as the target.

An effort is underway to get the tank farms to a "controlled, clean, and stable" condition including removing the equipment that had been abandoned in place over the years. Connections of unused instruments to risers are being removed. This ongoing project, which has been successfully completed in the TX farm, further reduces the surface targets of a tank. 
For target area of a tank with respect to significant energy deposition in the waste, the most straight-forward approach for this report is to assume the cross-sectional area of a tank $\left(5 \times 10^{-4} \mathrm{~km}^{2}\right)$. This value is quite conservative for most SST farms. There is a technical basis to assume $5 \times 10^{.5} \mathrm{~km}^{2}$ per tank based on field measurements and observations

\subsection{MISCELLANEOUS OBJECTS WITHIN THE TANKS}

In the future there may be additional equipment permanently installed into a tank which may be in contact with the waste without the removal of existing equipment.

In addition to the active equipment in or in close proximity to the waste, photos and videos and records verify other conductive material extending out of the waste toward the tank dome. This includes instruments or equipment (e.g., thermocouples, lances, etc.) abandoned in place over the years. Some of these were disconnected and dropped into the waste such that there is no direct connection to a riser providing a path for lightning current. Others may have been disconnected at the flange and left in place so there is a direct electrical path from the riser to the waste. It is impractical to try to identify each such object and categorize it with respect to its ability to act as a grounding rod.

It is possible for a lightning strike, if channeled down a riser, to spark across 1 to 2 meters of head space to objects protruding out of the waste or to equipment in nearby risers. An air gap of about $0.3 \mathrm{~m}$ (1 ft) normally precludes a spark between metal objects for potentials up to $140 \mathrm{kV}$. Schnetzer et al. (1995) report voltage transients as high as $200 \mathrm{kV}$ within a building during rocket-triggered lightning experiments on a reinforced concrete structure. This information presents some order of magnitude values of what can occur in a structure struck by lightning to better relate to metal objects in the tanks.

When there is a lightning strike in the vicinity of a tank, either to the ground or to a structure, the reinforced concrete tank will develop an electrical charge until the charge can dissipate into the ground. Equipment hanging into the waste from a riser can develop an induced charge such that it could spark in the waste to the metal tank which is connected to interconnecting pipes if that path has low enough resistance and inductive impedance to support the arc.

By including the "inactive" risers (i.e., those which do not have any equipment normally installed) in the riser target area discussed in section 4.3 above, the tank target includes those known and unknown items which are in the tanks as well as future additions.

\subsection{INTERCONNECTING PIPES}

There are underground interconnections for the tanks in the form of fill lines, cascade lines, etc. There are valve operators near the surface with reach rods to the valves in the pipes. 
These valve operators are normally in valve pits with covers over the pits. The valve operators are not plausible targets for a direct strike because the covers shield them.

The pipes are under $10 \mathrm{~m}(30 \mathrm{ft})$ or more of very resistive soil. It is very improbable that a lightning strike on the ground will lead to a significant energy transport to the tank although it possible a pipe could be charged by such a strike.

If lightning current were to be drawn through an interconnecting pipe from the ground or another tank, it could enter the metal tank to which it is connected through a "nozzle" arrangement. But the solid/liquid waste would probably not be affected because the current would have to find a path from the metal tank through the waste to some equipment out the top of the tank through a riser to ground. It is highly unlikely that such a path could introduce a significant amount of energy or cause a large spark. It is more likely that ground would be found through another pipe that is connected to the tank or through the concrete-tank/metal-tank interface, which has 1,000 to $1,400 \mathrm{~m}^{2}\left(10,000\right.$ to $\left.15,000 \mathrm{ft}^{2}\right)$ of contact surface, even though there is "insulating" material (e.g., Gunite) between the metal tank and the concrete tank. The interface has a large cross-sectional area. The condition of the waste in the tank is analogous to a person in a metal car or a person in a metal cage (Faraday cage) with millions of volts from a Van de Graaff generator passing through the cage (Newcott 1993).

Because of the low energy required to ignite flammable gas mixtures, it is reasonable to make the conservative assumption that any strike within a farm, including over buried pipes, will cause one or more sparks within each tank within the farm. Because of the higher energy required for ignition and the need for the energy to be deposited in the waste, that conservatism with respect to solid/liquid wastes is unnecessary.

\subsection{RISER GROUND CHARACTERISTICS}

There are several guides in effect for resistance to earth measurements that provide an acceptable level of protection from lightning for industrial facilities including hazardous storage facilities. Note that these standards and guides are based upon a measurement of direct current or low frequency alternating current, while lightning is high frequency.

IEEE Std 142 (1991) states, "System ground resistances of less than 1 ohm may...only be required for large substations, transmission lines, or generating stations. Resistances in the 1-5 ohm range are generally found suitable for industrial plant substations and buildings and large commercial installations."

NFPA 780 presently does not address the specific resistance acceptable for lightning protection systems. But its predecessor guide, NFPA 78 (1989), includes, "System ground resistances of less than $1 \mathrm{ohm}$ may be obtained by the use of individual electrodes connected together. Such a low resistance may only be required for large substations or generating 
stations. Resistances in the $25 \mathrm{ohm}$ range are generally found suitable for industrial plant substations and buildings and large commercial installations."

NAVFAC DM 4.6 states that maximum ground resistance for any lightning protection shall not exceed 10 ohms.

Article 250-84 of the National Electrical Code states that if a made electrode does not have a resistance-to-ground of 25 ohms or less, it shall be augmented with an additional electrode (NEC 1993). This is for the grounding of electrical systems. In 250-71(b) the Code notes in an example, "Also assume that the power ground has a resistance (Rp) of $10 \mathrm{ohms,} \mathrm{a} \mathrm{very}$ low value in most circumstances."

To determine the riser-to-ground resistance, a test was done on each accessible riser (some are under covers or cut off and capped below grade level) for each SST (Kiewert 1996). This test did not measure all characteristics of the tanks such as inductance. Five major conclusions the risers could be drawn:

- About $45 \%$ of the 100 -series tanks have all risers grounded adequately.

- The vast majority ( $>96 \%$ ) of the 885 originally installed risers in the 100 -series tanks are well grounded, meet the acceptance criteria of less than $5 \mathrm{ohms}$, and most have a resistance of less than 2 ohms.

- Those risers that were added to the 100 -series tanks after original construction are incidently grounded, if at all. Between $70 \%$ and $75 \%$ of those 202 risers had resistances in excess of the acceptance limit.

- The 200-series tanks (nominal capacity of $190,000 \mathrm{~L}\{50,000 \mathrm{gal}\}$ ) had a different construction technique for risers than the 100 -series tanks. About $2 / 3$ of the 97 risers on those 16 tanks were classified as ungrounded.

- Sixteen tanks (10 of the 200-series tanks) have temperature instruments that are grounded through the waste; i.e., the resistance of the instrument is less than the resistance of the riser.

These trends were not apparent from the work on SY-101 (Carios 1992) because of the limited scope of the investigation. Corrective actions, such as grounding straps, will be implemented on the risers that present a risk to the waste. If a specific riser cannot be grounded or bonded and it is one of concern with respect to tank penetration and/or waste composition, other mitigative actions, such as a grounded, metallic shed over the riser, may be required.

Appendix A presents more detail on applicable codes and guides. 


\subsection{EQUIPMENT/RISER BONDING CHARACTERISTICS}

The next item to consider is how well the equipment within the riser is bonded to the riser electrically to assure that it does not serve as a conduit for current into the waste or to its surface. In Cowley and Stepnewski (1994), Uman notes that a direct strike on equipment-riser bonds or welds with a standard value of $2.5 \times 10^{-3} \mathrm{Ohm}$ may generate voitages in the range of $10^{3}$ to $10^{4}$ Volts or "reasonable" values of 10 to 100 Volts. There may also be sparks at bolted flanges. If there is a small pocket of flammable gas in the riser, it is conceivable that it could ignite. However, since these effects are relatively localized and small or external to the tank, it is not of direct concern to the waste or structure.

But inadequate bonding would "guide" the current down the equipment into the tank where it would seek its way to ground through the waste, into the metal tank wall and into the concrete (which is a moderate conductor, similar in conductivity to earth). In taking this path, the lightning strike is capable of depositing significant amounts of energy in the waste, either through ohmic heating or an arc. Kjewert (1996) is proposing corrective actions to assure adequate bonding.

\subsection{TANK STRUCTURAL RESPONSE}

The following discussion addresses the issue of the potential direct effect of lightning upon the tank structure. It does not consider the pressure transient from a fire. It is applicable to tanks that neither have flammable gas concerns nor organic concerns as well as those that do. For this purpose, the tank farm area is considered as the target for lightning because the paths to the tank structure are many and even low energy effects should be considered. The specific concern is whether rebar that is wired tied together may create sparks with concrete spalling leading to strural effects.

While the paths that lightning may chose to take through a structure are becoming better understood through the emerging RF testing technique and computer analysis (which have not yet been done at Hanford), the Hanford waste tanks are not well enough understood to say with certainty what percentage of the current from a strike may pass from the riser to the rebar either through connections or arcs. Research, as described below, tends to demonstrate that rebar functions very well as a conductor. However, when it comes to detailed and specific analysis, Schnetzer et al. (1995) point out the difficulties of predicting a building's response to lightning, even when the building was built specifically for testing. In this case two subtle items caused responses that were unexpected. PVC pipe sleeves were installed on conduits to insulate the conduits from the building. But instead of extending the sleeves away from the building, they were cut off flush at the outer wall, allowing an unintended current path from the building to the exposed conduit at the point of exit. One of the two underground conduits used to evaluate the structure happened to be buried $3 \mathrm{~cm}(1.125 \mathrm{in}$.) under a metal post for a steel fence surrounding the building. When the conduit was excavated, substantial arcing spots were found on the top of the conduit confirming consistent arcing had occurred during the tests. With respect to the test, the authors say, "This 
outcome clearly demonstrates the difficulty in making definitive analytical assessments of the lightning responses of arbitrary complex structures or facilities." This experience points out the difficulty that would be encountered in modelling the 149 SSTs including the attached pipes and surrounding fences; light poles on the farms; other pipes, ducts, and conduits on the farms. But absent further information, it is safe to assume that in addition to the charge a tank receives through a riser, it is quite probable that the tank will be charged from a strike in the vicinity since it acts like a big electrode.

The rebar in the dome consists of two layers, one near the inner surface and one near the outer surface. Each layer consists of concentric rings and radial bars, like the spokes of a wheel. At some distance from the center, two bars were added for each one of the "spokes" to account for the ever-enlarging circumferences of the concentric circles. The bars were not welded, but the radial and circumferential were tied to each other to assure proper spacing between rings and spokes. So while there may be gaps at the joints between the radial lengths of rebar and other gaps where the circumferential lengths were joined, there are many effective paths for the current from radial to circumferential rebar and back, wherever low impedance exists.

Uman notes in Cowley and Stepnewski (1994), given gaps between rebar and risers and between rebar and rebar and between concrete and the metal tank wall and given lightning current passing through the reinforced concrete structure (including the waste tanks), it is probable that some sparks would occur. This sparking could cause damage to the concrete when the spark creates mini-explosions which presses the concrete outward, leading to cracks and/or spalling. This is a possibility particularly in structures in which the rebar network is limited.

Fagan and Lee (1970) discuss the grounding systems for buildings. They state, "...(T)hat concrete-encased metal objects were effective in providing improved grounding under adverse soil conditions suggests that the reinforcing framework of footings for the columns of structural steel buildings would provide effective grounding function and means... The steel framework of such buildings, if electrically connected at each column base to an inherent grounding electrode, then functions as a very efficient grounding network for system, lightning, and static grounding...All the rebar elements are held together before concrete pouring only by twisted-steel tie wires. As such, these fastenings would not be considered electrically adequate... At the same time, it has been found that these wire ties are surprisingly effective electrical connections...(T)here are a large number of these junctions (no. 8 or larger steel wire) effectively in parallel, cinched tightly together to support heavy rebar structures before and during the pouring of the concrete. They are also embedded in the concrete so corrosion is not a factor."

Assuming the reinforcing bar in a concrete reinforced structure is grounded, NFPA 780 (1995) states in 3-18.3, "Conductors...concealed in steel reinforced concrete units shall be connected to the reinforcing steel." "Conductors" are the down conductors from air terminals to ground. This connection is done to preclude inadvertent flashing between the down conductors and the structural steel. In other words, industry recognizes the ability of 
the rebar to be a pseudo down conductor without significant affects on the structure. Using this construction technique has not caused significant or unacceptable effects in the thousands of reinforced structures world-wide, including spalling caused by entrapped moisture vaporization.

IEEE Std 142 (1991) states, "Naturally, the greater the number of down conductors and grounding electrodes, the lower will be the voltage within the protection system, and the better it will perform. This is one of the great advantages of the steelframed building. It has as many down conductors as it has columns, or one about every $4.57 \mathrm{~m}$ (15 ft). Also at the bottom of each column it has a footing, which is a very effective electrode." With respect to ground electrodes, it states, "Made electrodes may be subdivided into ...steel reinforcing bars in below-grade concrete..." These statements are applicable to a reinforced concrete structure with its web of rebar. And for an underground, reinforced concrete tank, the whole structure is the equivalent of a foundation.

As is the case with any electrical current, current associated with a lightning strike will take the path of least impedance. The case of lightning strike is a very dynamic situation with the large current, resistance, inductive, and capacitive effects in the many possible paths. If a strike were to occur on a tank riser that is not well grounded to earth ground and instead the current's primary path is through reinforcing bars that are joined but not welded, the current would tend to go through the paths in which the connection is better than where significant gaps exist. In the case of an above-ground building that has the lightning current pass through the reinforcing steel and/or rebar, it is anticipated that the rebar is integral with the foundation where the current will be dissipated into the ground with no damage to the building. In the case of the underground tanks at Hanford, the rebar is not only tied into the foundation, the concrete walls, which have a conductivity lower than the backfill around the tank, will dissipate the current through the large surface area of $1900 \mathrm{~m}^{2}\left(20,000 \mathrm{ft}^{2}\right)$.

Two papers concerning rocket-triggered lightning relate to concrete reinforced structures. Morris et al. (1994) confirmed computer modelling of weapons storage igloos with respect to lightning including rebar and a Lightning Protection System (LPS). They state in the conclusions, "...direct-strike lightning appears to pose no safety threat to properly stored explosives inside the structure... The surge impedance through the structure rebar is so small compared to the surge impedance of the counterpoise or other LPS conductors, that the LPS serves principally to conduct the lightning current into the rebar... Only a small percentage of the total current flows on IPS conductors, so most of the total current flows to infinity through the rebar, concrete, earth, and possibly large diameter metallic conduits... The voltages inside the structure are determined principally by the inductance and connectivity of the rebar in the walls and floor, and the current. flowing in conductors connected to the grounding system is determined by the parallel inductance of the rebar."

A second paper, by Schnetzer et al. (1995), evaluated the response of a structure specifically constructed to be struck by rocket-triggered lightning. The walls were isolated from the ground and the building footing by a phenolic insulating material and were bonded to the floor rebar for some tests and isolated from the floor rebar for other tests. The structure had 
an LPS including 5 air terminals, 2 down conductors, and a Ground Ring Electrode (GRE). The air terminals were bonded to the corrugated metal roof which was bonded to the rebar in the walls. The building was built on $0.15 \mathrm{~m}$ ( 6 in.) limestone gravel base eliminating intimate contact with the underlying red clay soil. As noted in the previous paper, this paper concludes, "In this type of steel-reinforced concrete structure, structural members carry to earth the major fraction of incident lightning current... With wall-to-floor bonding jumpers removed, it was expected that the majority of the current would be carried to earth by the down conductors. In fact, this path carried no more than one-half to one-third of the incident stroke current." Even though the walls were intentionally insulated from the footings and the ground, this significant amount of current was carried by the rebar through unanticipated paths to ground.

IEEE Std 142 (1991) reports in the paragraph about concrete encased electrodes, "Concrete below ground is a semi-conductive median of about $3000 \mathrm{ohm} \mathrm{cm}$ resistivity at $20^{\circ} \mathrm{C}$ or somewhat lower than the average loam soil. Consequently, in earth of average to high resistivity, the encasement of rod or wire electrodes in concrete results in lower resistance than when a similar electrode is placed directly in the earth." The measured resistivity of Hanford's soil is 10,000 to $50,000 \mathrm{ohm} \mathrm{cm}$ (Kiewert 1996). If one were to visualize the layers of an onion with an electrode buried in the center, one can imagine that, even though the resistance of each layer has the same value for each $\mathrm{cm}^{2}$, the folded back layers have smaller areas meaning that the shells' resistances increase as one progressively peels shell-by-shell away toward the electrode at the center. By having material immediately around the electrode with a relatively low resistivity (such as concrete) instead of high resistivity (such as Hanford soil), the resistance of the first shell of soil is reduced because the area is larger than if it were immediately around the electrode (i.e., not displaced by the concrete).

API (1991) recognizes that there are underground storage tanks that are used to store petroleum products, including tanks in non-conductive, plastic outsides. With respect to a concern about static charges, they state, "...the outside of a buried plastic tank is in contact with a conducting medium and any accumulated charges are dissipated."

Weiner (1996) reviewed the structural aspects of potential lightning effects on a tank. He concludes that, "Dome collapse as a direct result of a strike is considered very unlikely." This is because of practical experience, the fact the domes have at least double the normal structural margin implied by code practice, and any damage would be local spalling period. In addition, the multiplicity of conducting paths tends to minimize any localized reactions.

Based on the historical information of experience of buildings of similar construction, testing that was done (mostly reported in IEEE documents), and a review of design features of the waste tanks, the tank structure will not be directly affected by a lightning strike. This section does not address the consequences of a secondary effect from a detonation or deflagration, were one to occur. 


\subsection{MITIGATION}

For a system like the tank farms, there are several possible methods to reduce the threat from lightning. These methods include:

1. Improved grounding of the risers and bonding of the equipment that passes through them to the waste

2. Grounded air terminals around the tanks

3. Shielding which covers the tanks, such as a catenary system

4. Mitigative steps to reduce the vulnerabilities of the waste such as ventilation or assuring the waste is wet

5. Operational controls which prevent or mitigate enhanced lightning vulnerabilities during normal and special operations.

Grounding and Bonding The 100-series Single Shell Tanks were constructed (albeit possibly inadvertently) as rather effective Faraday Cages in that the original risers are, in general, tied into the rebar network. Those risers added after original construction and those of the 200-series tanks can be grounded through the addition of cables better coupling the riser to ground. The cables should be as short and fat as reasonable to reduce the impedance as much as possible, or more than one cable should be used. There are some instruments that contact the waste and are apparently grounded through the waste instead of through the riser. These instruments have to be carefully considered as to the waste in the particular tank, the need for the instrument, its design and installation, and the ability to bond the instrument better to the riser or other path to ground.

Grounded Air Terminals The existing light fixtures on the poles within the farms already present attractive lightning targets. However, there is no engineered protection to keep a streamer from initiating from a riser, ventilation system, earth ground, etc., and jumping to a conduit affixed to a light pole. A system of partial protection on existing poles would serve to intercept and divert some of the infrequent flashes that might otherwise affect a tank with its contained waste, particulariy for those farms with waste that is most susceptible to ignition. The AX-and T-farms do not have poles close enough to the tanks to have protection value. $\mathrm{C}$-farm has new, tall, metal light poles that have air terminals installed already. The grounding of the lightning protection needs to be checked to assure it is independent of the electrical system. Because of the configuration of the existing light poles, B-, BX-, BY-, S-, SX-, and U-farms can achieve 40\%-60\% protection while A-, TX-, and TY-farms can achieve $25 \%-40 \%$ protection. ICF Kaiser Hanford provided an estimate of $\$ 350,000$ to install air terminals on about 40 existing light poles (Koellermeier 1996).

Additional poles with attached grounded air terminals could be installed where existing light poles do not provide $100 \%$ coverage. This would be more costly in resources and 
occupational exposure and disruptive to ongoing work than limiting the work to existing poles. This is not recommended for the incremental benefit received.

Catenary System A review of previous mitigation activities was done. Because of the concern of gas release events in 101-SY in the early 90 s, consultants were brought onsite to propose appropriate lightning mitigation. Two meteorological towers were put into place as air terminal towers. Eventually they were removed so that certain work could take place and because the system was not fully effective as installed. While they were more than tall enough to provide protection, there was a question of the cone of protection coverage. Because the lightning season had passed and the mixer pump was subsequently installed, no mitigation system was reinstalled.

This episode was a learning process in that it became evident that any significant mitigation scheme would have to be carefully considered so as to not present a hazard to the workers or a significant barrier to accomplishing work in the farms.

ABB Impell Corporation; TLC, Incorporated; and EBASCO Incorporated provided input to the decision for SY-101. Johns (1991) presented the review of the proposals. The consensus was that installation of a catenary system for the SY Farm instead of the air terminal towers would provide better protection for SY-101. The estimate for this protection was $\$ 200,000$. Engelhardt (1992) stated the cost of a catenary system for SY Farm was $\$ 400,000$. In view of the complexity of accessing for work one can estimate the installation of the commonly accepted, "best" protection would be hundreds of thousands of dollars for each of the twelve single-shell-tank farms. Installation of catenary systems for all tanks would itself entail some risk due to digging activities for installation. An evaluation of this risk was beyond the scope of this paper.

Waste Controls Most of this report has focussed on what happens outside the tank when there is a lightning strike. Another mitigative action would be to affect the waste in such a way that a lightning strike that does impact the waste does not create an ignition. If tanks have flammable gas concentrations an unacceptably high amount of time, ventilation may be used to control the gas levels. If there are fuel-rich pockets of organic waste that are dry enough to ignite, depending on the leak integrity of the tank, it may be possible to add water to the waste to keep it above the required moisture level. Waste controls are not recommended if they are only for prevention of ignition from lightning unless there is some new analysis of waste vulnerability which warrants the controls.

Operational Controls Operational controls, such as posted weather watchers, contacts with the Hanford Weather Observatory, termination of work, bonding of in-use equipment, are not in the scope of this report. Those controls are imposed in the work control process. While this report recognizes that controls exist, it is limited to protection for storage conditions.

Recommendation To address lightning mitigation acioss all the SST farms, the National Lightning Safety Institute was contracted to review the farms, tanks, and area, to propose a 
practical mitigation approach. Among other things, they strongly recommend grounding and bonding. They also recommended the addition of grounded air terminals atop existing wooden light masts/poles correctly mounted and grounded. (Kithill and Collier 1996) For the newer steel poles (i.e., C-tank farm), they recommended verifying the lightning ground system is not tied into the electrical ground system. It is recognized that this is not "100\% protection." But it is balanced approach considering the relatively low frequency of a lightning strike affecting a tank and the cost and risk of constructing a more elaborate system.

\subsection{CONCLUSIONS}

For considerations of either structural or flammable gas issues, any strike on a farm should be assumed as an event initiator. That is about $0.02 \mathrm{~km}^{2}$ for each farm. For concerns for organic issues (either solvents or complexants), the target for each tank is less than $500 \mathrm{~m}^{2}$ or $5 \times 10^{-4} \mathrm{~km}^{2}$ (the cross-sectional area of the tank). This is conservative by a factor a $2-10$ because on most SST farms the ground above the tanks is relatively clear of pipes, ducts, and conduits. The tark risers either are adequately grounded or will be grounded in accordance code acceptance criteria. The tank structures are not significantly affected by a lightning-initiated event because of the many paths through the rebar and to ground through the concrete. Structural failure caused directly by lightning is incredible. Full mitigation, such as a catenary system for the 12 SST farms, would cost several million dollars. A more cost-effective approach would be to install air terminals on existing light poles.

\subsection{REFERENCES}

API, 1991, Protection Against Ignitions Arising out of Static, Lightning, and Stray Currents, API Recommended Practice 2003, Fifth Edition, American Petroleum Institute, Washington, D.C.

Buck, F. G., 1993, Potential Lightning Strike Events, PNL-9800, Pacific Northwest Laboratory, Richland, Washington.

Carlos, W. C., 1992, Test Report and Evaluation of the Resistance-to-Earth Measurements in the 241-SY Tank Farm, WHC-SD-WM-TRP-057, Revision 0, Westinghouse Hanford Company, Richland, Washington.

Cowley, W. L., D. D. Stepnewski, 1994, Evaluation of Hazards from Lightning Strikes to Tank Farm Facilities, WHD-SD-WM-SARR-027, Revision 0, Westinghouse Hanford Company, Richland, Washington.

Department of Navy, 1979, Lightning \& Cathodic Protection Design Manual, NAVFAC DM-4.6. 
Engelhardt, K. L., 1992, Lightning Protection, Draft, Westinghouse Hanford Company, Richland, Washington.

Fagan, E. J., R. H. Lee, 1970, The Use of Concrete-Enclosed Reinforcing Rods as Grounding Electrodes, IEEE Transactions on Industry and General Applications, Volume IGA-6, No. 4, July/August 1970, Institute of Electrical and Electronic Engineers, Inc., New York, New York.

IEEE Std 142, 1991, IEEE Recommended Practice for Grounding of Industrial and Commercial Power Systems, Institute of Electrical and Electronics Engineers, Inc., New York, New York.

Huckfeldt, R. A., 1996, Electrical Hazard Classification Study for the Flammable Gas Watch List Tanks, WHC-SD-WM-HC-017, Revision 0, Westinghouse Hanford Company, Richland, Washington.

Kiewert, 1996, Single-Shell Tank Riser Resistance to Ground Test Report, WHC-SD-WM-TR-034, Revision 0, Westinghouse Hanford Company, Richland, Washington.

Koellermeier, E. M., 1996, Tank Farm Lightning Mitigation Estimate, Work Order E23494, EMK-96-0001, ICF Kaiser Hanford Company, Richland, Washington.

Kithil, R., R. S. Collier, 1996, Lightming Safety at the Hanford Facility, National Lightning Safety Institute, Louisville, Colorado.

Morris, M. E., R. J. Fisher, G.H. Schnetzer, K.O. Merewether, R.E. Jorgenson, 1994, Rocket-Triggered Lightning Studies for the Protection of Critical Assets, IEEE

Transactions on Industry Applications, Volume 30, No. 3, May/June 1994, Institute of Electrical and Electronic Engineers, Inc., New York, New York.

Newcott, W. R., 1993, Lightning, Nature's High-Voltage Spectacle, July, 1993, National Geographic Magazine, Washington, D.C.

NEC, 1993, National Electrical Code - 1993, National Fire Protection Association, Quincy, Massachusetts.

NFPA 78, 1989, Lightning Protection Code, National Fire Protection Association, Quincy, Massachusetts.

NFPA 497A, 1992, Recommended Practice for Classification of Class I Hazardous (Classified) Locations for Electrical Installations in Chemical Installations in Chemical Process Areas, National Fire Protection Association, Quincy, Massachusetts. 
NFPA 780, 1995, Standard for Installation of Lightning Protection Systems, National Fire Protection Association, Quincy, Massachusetts.

Schnetzer, G. H., J. Chael, R. Davis, R. J. Fisher, P. J. Magnotti, 1995, 1994 Triggered Lighming Test Program: Measured Responses of a Reinforced Concrete Building Under Direct Lightning Attachments, SAND95-1151/1, Sandia National Laboratories, Albuquerque, New Mexico.

Weiner, E. O., 1996, Lightning Structural Effects on High Level Waste Tanks - White Paper, ICF Kaiser Hanford Company, Richland, Washington. 
Table 4-1. Riser Configuration with Respect to Lightning for $\mathrm{A}, \mathrm{BX}$, and $\mathrm{T}$ Farms. (12 sheets)

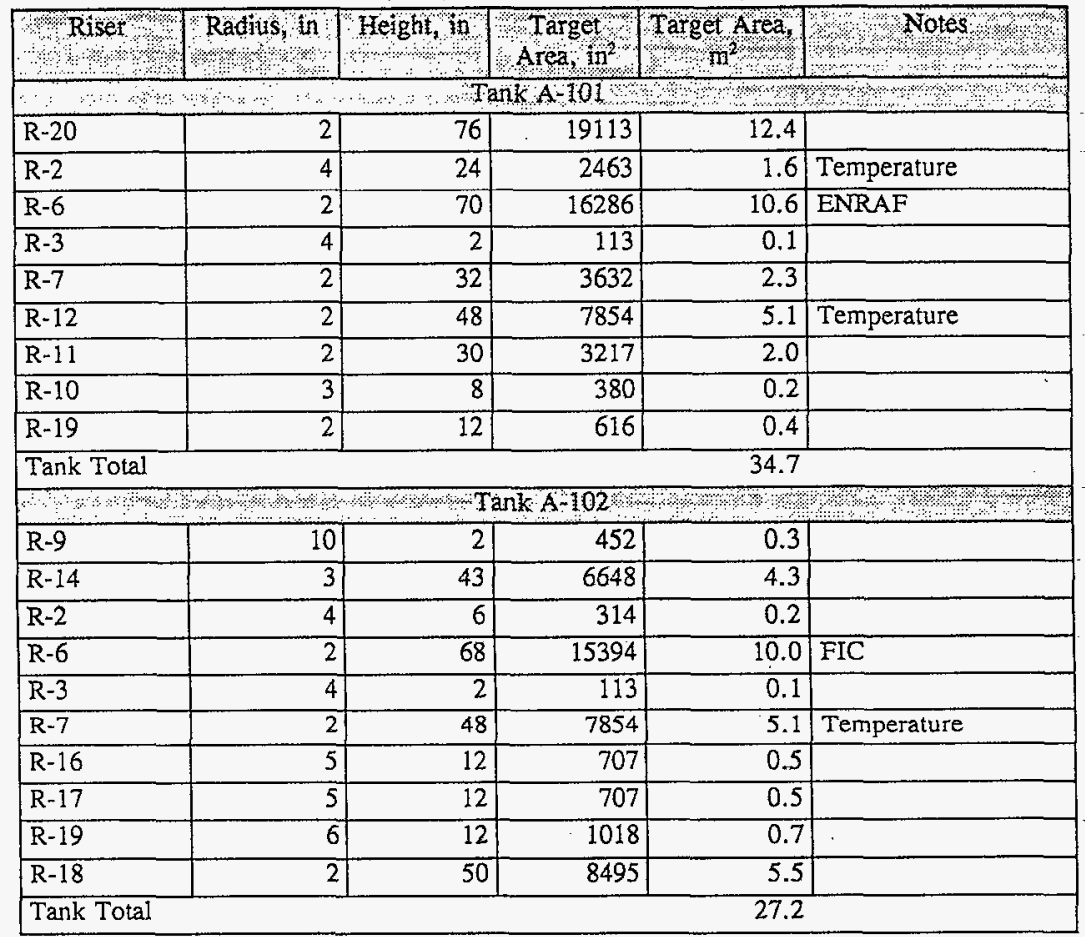


Table 4-1. Riser Configuration with Respect to Lightning for $\mathrm{A}, \mathrm{BX}$, and $\mathrm{T}$ Farms. (12 sheets)

\begin{tabular}{|c|c|c|c|c|c|}
\hline Riset & Radius, th & Heigh, in & $\begin{array}{l}\text { Target } \\
\text { Area, in }\end{array}$ & Target Area & \% Notes \\
\hline \multicolumn{6}{|c|}{ 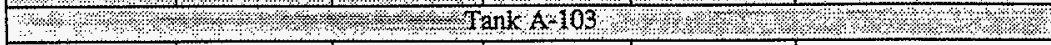 } \\
\hline $\mathrm{R}-15$ & 2 & 54 & 9852 & 6.4 & Temperature \\
\hline $\mathrm{R}-2$ & 4 & 18 & 1810 & 1.2 & Temperature \\
\hline R-6 & 2 & 67 & 14957 & 9.7 & FIC \\
\hline $\mathrm{R}-17$ & 2 & 56 & 10568 & 6.9 & \\
\hline $\mathrm{R}-12$ & $\overline{6}$ & 24 & 2827 & 1.8 & \\
\hline $\mathrm{R}-3$ & 4 & 2 & 113 & 0.1 & \\
\hline R-7 & 2 & 24 & 2124 & 1.4 & \\
\hline $\mathrm{R}-11$ & 4 & 6 & 314 & 0.2 & \\
\hline R-19 & 2 & 8 & 314 & 0.2 & Liq. Observ. Well \\
\hline \multicolumn{3}{|l|}{ Tank I } & & 27.9 & \\
\hline
\end{tabular}


Table 4-1. Riser Configuration with Respect to Lightning for $A, B X$, and T Farms. (12 sheets)

\begin{tabular}{|c|c|c|c|c|c|}
\hline Riser & Radjus, in & Hejght, in & $\begin{array}{l}\text { Target } \\
\text { Area } \text { in }^{2}\end{array}$ & Targetsrea, & (1) Notes \\
\hline \multicolumn{6}{|c|}{ से } \\
\hline $\mathrm{R}-15$ & 2 & 30 & 3217 & 2.1 & \\
\hline $\mathrm{R}-20$ & 2 & 18 & 1257 & 0.8 & \\
\hline $\mathrm{R}-5$ & 2 & 40 & 5542 & 3.6 & \\
\hline $\mathrm{R}-1$ & 4 & 18 & 1521 & 1.0 & \\
\hline $\mathrm{R}-14$ & 2 & 48 & 7854 & 5.1 & \\
\hline $\mathrm{R}-10$ & 2 & 14 & 804 & 0.5 & \\
\hline R-6 & 2 & 52 & 9161 & 6.0 & Reel \\
\hline R-2 & 4 & 18 & 1521 & 1.0 & Temperature \\
\hline $\mathrm{R}-11$ & 2 & 15 & 908 & 0.6 & \\
\hline $\mathrm{R}-18$ & 2 & 12 & 616 & 0.4 & Temperature \\
\hline $\mathrm{R}-12$ & 2 & 12 & 616 & 0.4 & Temperature \\
\hline R-4 & 6 & 8 & 616 & 0.4 & \\
\hline $\mathrm{R}-17$ & 6 & 22 & 2463 & 1.6 & \\
\hline \multicolumn{6}{|c|}{ Tank Total 23.5} \\
\hline \multicolumn{6}{|c|}{ S. } \\
\hline R-11 & 1 & 24 & 1963 & 1.3 & \\
\hline R-5 & 2 & $\overline{56}$ & 10568 & 6.9 & Reel \\
\hline $\mathrm{R}-1$ & 4 & 10 & 616 & 0.4 & \\
\hline R-14 & 2 & 6 & 201 & 0.1 & Temperature \\
\hline $\mathrm{R}-15$ & 2 & 52 & 9160 & 6.0 & Temperature \\
\hline R-6 & 2 & 24 & 2124 & 1.4 & \\
\hline R-16 & 2 & 84 & 23235 & 15.1 & Temperature \\
\hline R-17 & 2 & 68 & 15395 & 10.0 & Temperature \\
\hline R-18 & 2 & 3 & 79 & 0.1 & \\
\hline R-19 & 2 & 72 & 17203 & 11.2 & Temperature \\
\hline R-9 & 4 & 98 & 32685 & 21.2 & Temperature \\
\hline R-20 & 2 & 6 & 201 & 0.1 & \\
\hline $\mathrm{R}-4$ & 6 & 10 & 804 & 0.5 & \\
\hline $\mathrm{R}-8$ & 2 & 12 & 616 & 0.4 & Pressure Gauge \\
\hline $\mathrm{R}-21$ & 2 & 72 & 17203 & 11.2 & Vapor Sampler \\
\hline R-22 & 2 & 48 & 7854 & 5.1 & Temperature \\
\hline \multicolumn{6}{|c|}{ Tank Total 91.0} \\
\hline
\end{tabular}


Table 4-1. Riser Configuration with Respect to Lightning for $A, B X$, and $T$ Farms. (12 sheets)

\begin{tabular}{|c|c|c|c|c|c|}
\hline Riser & Radius, in & Height, in & $\begin{array}{l}\text { Target } \\
\text { Area } \mathrm{n}^{2}\end{array}$ & $\begin{array}{c}\text { Target } 1 \mathrm{uea} \\
\mathrm{n}^{2}\end{array}$ & (4) Notes \\
\hline \multicolumn{6}{|c|}{ 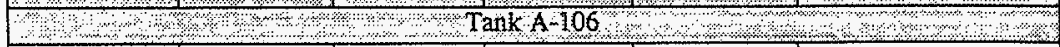 } \\
\hline R-20 & 3 & 18 & 1385 & 0.9 & \\
\hline$\overline{\mathrm{R}-1}$ & 4 & 2 & 113 & 0.1 & \\
\hline R-14 & 2 & 48 & 7854 & 5.17 & Temperature \\
\hline $\mathrm{R}-10$ & 3 & 24 & 2290 & 1.5 & \\
\hline R-6 & 2 & 62 & 12868 & 8.4 & ENRAF \\
\hline $\mathrm{R}-2$ & 4 & 16 & 1257 & 0.8 & Temperature \\
\hline $\mathrm{R}-11$ & 3 & 24 & 2290 & 1.5 & \\
\hline $\mathrm{R}-18$ & 2 & 48 & 7854 & 5.1 & \\
\hline R-12 & 3 & 16 & 1134 & 0.7 & \\
\hline$\overline{R-17}$ & 6 & 16 & 1521 & \multirow{2}{*}{\multicolumn{2}{|c|}{$\begin{array}{r}1.0 \\
25.1 \\
\end{array}$}} \\
\hline \multicolumn{4}{|l|}{ Tank Total } & & \\
\hline \multicolumn{4}{|c|}{ FARM TOTAL/AVE PER TANK } & \multicolumn{2}{|l|}{$229.4 / 38.2$} \\
\hline \multicolumn{6}{|c|}{ 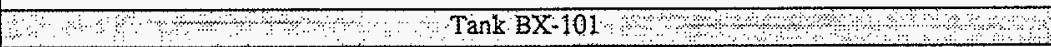 } \\
\hline R-7 & 6 & 20 & 2123 & 0.4 & \\
\hline R-8 & 2 & 57 & 10936 & 7.1 & Reel \\
\hline R-2 & 2 & 62 & 12868 & 8.4 & Temperature \\
\hline $\mathrm{R}-1$ & 2 & 69 & 15837 & \multirow{2}{*}{\multicolumn{2}{|c|}{$\frac{10.3}{26.2}$}} \\
\hline \multicolumn{4}{|l|}{ Tank Total } & & \\
\hline \multicolumn{6}{|c|}{ Tank BX-102 } \\
\hline R-7 & 6 & 72 & 19113 & 12.4 & \\
\hline R-8 & 2 & 44 & 6648 & 4.3 & Temperature \\
\hline$\overline{\mathrm{R}-2}$ & 2 & 59 & 11690 & 7.6 & Reel \\
\hline \begin{tabular}{|l|} 
R-1 \\
\end{tabular} & 2 & 28 & 2827 & 1.8 & Temperature \\
\hline \multicolumn{4}{|l|}{ Tank Total } & \multicolumn{2}{|c|}{\begin{tabular}{r|l}
1.8 & Temperature \\
26.1
\end{tabular}} \\
\hline \multicolumn{4}{|c|}{ Tank BX-103 } & \multicolumn{2}{|l|}{8} \\
\hline $\mathrm{R}-7$ & 6 & 16 & 1521 & 1.0 & \\
\hline $\mathrm{R}-8$ & 2 & 69 & 15837 & 10.3 & FIC \\
\hline $\mathrm{R}-2$ & 2 & 60 & 12076 & 7.8 & \\
\hline $\mathrm{R}-1$ & 2 & 45 & 6940 & 4.5 & Temperature \\
\hline \multicolumn{3}{|l|}{\begin{tabular}{|l|} 
Tank Total \\
\end{tabular}} & \multicolumn{3}{|c|}{23.6} \\
\hline
\end{tabular}


Table 4-1. Riser Configuration with Respect to Lightning for $A, B X$, and $T$ Farms. (12 sheets)

\begin{tabular}{|c|c|c|c|c|c|}
\hline Riser & Radius, & Height in & $\begin{array}{l}\text { Target } \\
\text { Area, } \mathrm{n}^{2}\end{array}$ & Target Area, & Notes \\
\hline \multicolumn{6}{|c|}{$1018, \quad \operatorname{Tank} B X-104 \%$} \\
\hline R-7 & 6 & 12 & 1018 & 0.7 & \\
\hline R-8 & 2 & 69 & 15837 & 10.3 & ENRAF \\
\hline $\mathrm{R}-1$ & 2 & 96 & 30172 & 19.6 & \\
\hline \multicolumn{4}{|l|}{ Tank Total } & \multicolumn{2}{|l|}{30.6} \\
\hline \multicolumn{4}{|c|}{$\therefore \ldots$} & \multicolumn{2}{|c|}{ 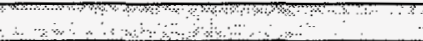 } \\
\hline R-7 & 6 & 65 & 15837 & 10.3 & Temperature \\
\hline$\overline{R-8}$ & 2 & 58 & 11310 & 7.4 & \\
\hline$\overline{R-2}$ & 6 & 18 & 1810 & 1.2 & \\
\hline R-1 & 2 & 69 & 15837 & 10.3 & ENRAF \\
\hline \multicolumn{4}{|l|}{ Tank Total } & \multicolumn{2}{|l|}{29.2} \\
\hline \multicolumn{6}{|c|}{ 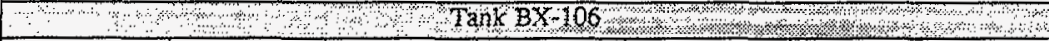 } \\
\hline $\mathrm{R}-8$ & 2 & 65 & 14103 & 9.2 & ENRAF \\
\hline R-7 & 6 & 69 & 17671 & 11.5 & Temperature \\
\hline R-1 & 2 & 26 & 2463 & 1.6 & Temperature \\
\hline R-2 & 2 & 108 & 38013 & 24.7 & \\
\hline \multicolumn{4}{|l|}{ Tank Total } & \multicolumn{2}{|c|}{47.0} \\
\hline \multicolumn{6}{|c|}{ Tark BX $-107 \mathrm{~N}$, } \\
\hline R-5 & 2 & 20 & 1521 & \multicolumn{2}{|l|}{1.0} \\
\hline$R-\overline{6}$ & 6 & 22 & 2463 & \multicolumn{2}{|l|}{1.6} \\
\hline$\overline{R-7}$ & 6 & 22 & 2463 & \multicolumn{2}{|l|}{1.6} \\
\hline R-8 & 2 & 72 & 17203 & \multicolumn{2}{|c|}{\begin{tabular}{l|l|}
11.2 & FIC \\
\end{tabular}} \\
\hline$\overline{\mathrm{R}-2}$ & 6 & 68 & 17203 & \multicolumn{2}{|l|}{11.2} \\
\hline $\mathrm{R}-3$ & 6 & 40 & 6648 & \multicolumn{2}{|l|}{4.3} \\
\hline $\mathrm{R}-4$ & 2 & 65 & 14103 & 9.2 & Temperature \\
\hline \multicolumn{6}{|c|}{40.0} \\
\hline
\end{tabular}


Table 4-1. Riser Configuration with Respect to Lightning for $\mathrm{A}, \mathrm{BX}$, and T Farms. (12 sheets)

\begin{tabular}{|c|c|c|c|c|}
\hline Riser & Radius, in & $\begin{array}{l}\text { Target } \\
\text { Area, }\end{array}$ & Target Area & \% Notes \\
\hline \multicolumn{5}{|c|}{ ४ै। } \\
\hline $\mathrm{R}-8$ & 2 & 2463 & 1.6 & \\
\hline $\mathrm{R}-7$ & 6 & 12868 & 8.4 & Reel \\
\hline $\mathrm{R}-6$ & 6 & 3217 & 2.1 & \\
\hline $\mathrm{R}-5$ & 2 & 17203 & 11.2 & Temperature \\
\hline $\mathrm{R}-13$ & 6 & 3217 & 2.1 & \\
\hline $\mathrm{R}-1$ & 2 & 10568 & 6.9 & \\
\hline $\mathrm{R}-2$ & 6 & 3217 & 2.1 & \\
\hline \multicolumn{3}{|l|}{ Tank Total } & \multicolumn{2}{|l|}{34.4} \\
\hline \multicolumn{3}{|c|}{$\therefore \quad \cdots \quad \therefore \quad \cdots$} & \multicolumn{2}{|c|}{ की } \\
\hline R-5 & 2 & 5542 & 3.6 & Temperature \\
\hline R-6 & $\overline{6}$ & 1018 & 0.7 & \\
\hline R-7 & 6 & 1662 & 1.1 & \\
\hline R-8 & 2 & 14103 & 9.2 & ENRAF \\
\hline R-1 & 2 & 804 & 0.5 & \\
\hline $\mathrm{R}-2$ & 6 & 2123 & 1.4 & \\
\hline $\mathrm{R}-3$ & 6 & 7238 & 4.7 & Temperature \\
\hline $\mathrm{R}-4$ & 2 & 14103 & 9.2 & \\
\hline \multicolumn{3}{|l|}{ Tank Total } & \multicolumn{2}{|l|}{$\frac{9.21}{30.4}$} \\
\hline \multicolumn{5}{|c|}{ - } \\
\hline $\mathrm{R}-6$ & 6 & 1810 & \multicolumn{2}{|c|}{1.2} \\
\hline $\mathrm{R}-5$ & 2 & 1810 & \multicolumn{2}{|l|}{1.2} \\
\hline $\mathrm{R}-4$ & 2 & 11310 & \multicolumn{2}{|l|}{7.4} \\
\hline $\mathrm{R}-3$ & 6 & 5281 & \multicolumn{2}{|l|}{3.4} \\
\hline $\mathrm{R}-2$ & 6 & 11690 & \multicolumn{2}{|c|}{\begin{tabular}{l|l|}
7.6 & Reel \\
\end{tabular}} \\
\hline R-1 & 2 & 11310 & \multicolumn{2}{|c|}{\begin{tabular}{l|l|}
7.4 & Temperature \\
\end{tabular}} \\
\hline R-RI & 2 & 210 & \multicolumn{2}{|l|}{0.1} \\
\hline $\mathrm{R}-\mathrm{R} 2$ & 2 & 314 & \multicolumn{2}{|l|}{0.2} \\
\hline \multicolumn{5}{|c|}{28.5} \\
\hline
\end{tabular}


Table 4-1. Riser Configuration with Respect to Lightning for A, BX, and T Farms. (12 sheets)

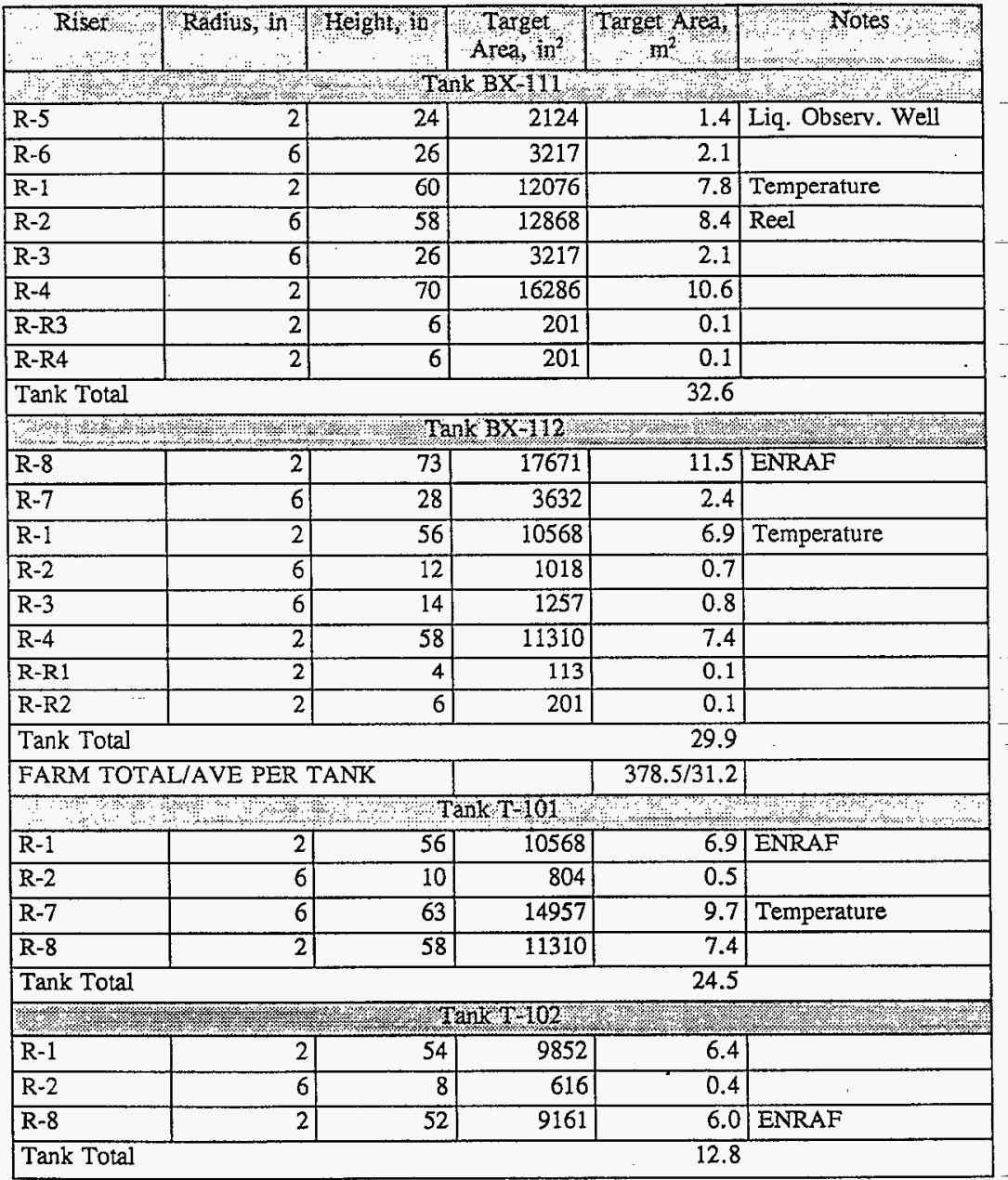


Table 4-1. Riser Configuration with Respect to Lightning for $\mathrm{A}, \mathrm{BX}$, and $\mathrm{T}$ Farms. (12 sheets)

\begin{tabular}{|c|c|c|c|c|c|}
\hline Riset & Radius, in & Height o & $\begin{array}{l}\text { Target } \\
\text { Area, } \mathrm{n}^{2}\end{array}$ & Target Area & Notes \\
\hline \multicolumn{6}{|c|}{ Tank T-103 } \\
\hline $\mathrm{R}-1$ & 2 & 63 & 13273 & 8.6 & ENRAF \\
\hline$\overline{\mathrm{R}-2}$ & 6 & 8 & 616 & 0.4 & \\
\hline $\mathrm{R}-7$ & 6 & 61 & 14103 & 9.2 & \\
\hline$\overline{\mathrm{R}-8}$ & 2 & 59 & 11690 & 7.6 & Temperature \\
\hline \multicolumn{4}{|l|}{ Tank Total } & $\overline{25.8}$ & \\
\hline \multicolumn{6}{|c|}{ (1) } \\
\hline $\mathrm{R}-1$ & 2 & 10 & 452 & 0.3 & Liq. Observ. Well \\
\hline $\mathrm{R}-2$ & 6 & 28 & 3632 & 2.4 & \\
\hline R-3 & 6 & 20 & 2124 & 1.4 & Vap. Temp. Probe \\
\hline $\mathrm{R}-4$ & 2 & 53 & 9503 & 6.2 & Temperature \\
\hline $\mathrm{R}-5$ & 2 & 60 & 12076 & 7.8 & ENRAF \\
\hline $\mathrm{R}-6$ & 6 & 12 & 1018 & 0.7 & \\
\hline $\mathrm{R}-7$ & 6 & 31 & 4301 & 2.8 & \\
\hline R-8 & 2 & 50 & 8495 & 5.5 & \\
\hline \multicolumn{4}{|l|}{ Tank Total } & 27.1 & . \\
\hline \multicolumn{6}{|c|}{$\operatorname{Tan} \mathrm{K}-105$} \\
\hline$R-1$ & 2 & 60 & 12076 & 7.8 & ENRAF \\
\hline R-2 & 6 & 9 & 707 & 0.5 & \\
\hline R-3 & 6 & 5 & 380 & 0.2 & \\
\hline R-4 & 2 & 7 & 254 & 0.2 & Temperature (cut) \\
\hline R-5 & 2 & 54 & 9852 & 6.4 & \\
\hline R-6 & 6 & 31 & 4301 & 2.8 & \\
\hline $\mathrm{R}-8$ & 2 & 12 & 616 & 0.4 & \\
\hline \multicolumn{4}{|l|}{ Tank Total } & 18.3 & \\
\hline
\end{tabular}


Table 4-1. Riser Configuration with Respect to Lightning for $\mathrm{A}, \mathrm{BX}$, and $\mathrm{T}$ Farms. (12 sheets)

\begin{tabular}{|c|c|c|c|c|c|}
\hline Riser & Radius, in & Height in & Target & 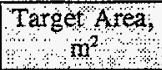 & Notes \\
\hline \multicolumn{6}{|c|}{ 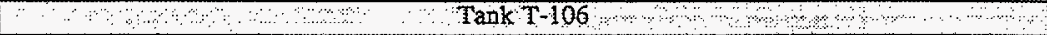 } \\
\hline $\mathrm{R}-1$ & 2 & 60 & 12076 & 7.8 & ENRAF \\
\hline $\mathrm{R}-2$ & 6 & 16 & 1520 & 1.0 & \\
\hline R-3 & 6 & 12 & 1018 & 0.7 & \\
\hline $\mathrm{R}-4$ & 2 & 4 & 113 & 0.1 & \\
\hline R-13 & 6 & 71 & 18626 & 12.1 & \\
\hline R-5 & 2 & 10 & 452 & 0.3 & \\
\hline $\mathrm{R}-6$ & 6 & 10 & 804 & 0.5 & \\
\hline $\mathrm{R}-7$ & 6 & 32 & 4536 & 2.9 & \\
\hline R-8 & 2 & 58 & 11310 & 7.4 & Temperature \\
\hline \multicolumn{6}{|c|}{ Tank Total 32.8} \\
\hline \multicolumn{6}{|c|}{ 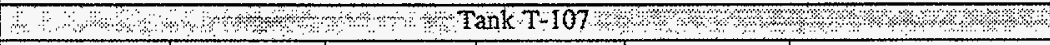 } \\
\hline R-RI & 2 & $\overline{2}$ & 50 & 0.0 & \\
\hline $\mathrm{R}-1$ & 2 & 63 & 13273 & 8.6 & ENRAF \\
\hline$\sqrt{\mathrm{R}-2}$ & 6 & 12 & 1018 & 0.7 & \\
\hline R-3 & 6 & 16 & 1520 & 1.0 & Dip Tubes \\
\hline $\mathrm{R}-4$ & 2 & 58 & 11310 & 7.4 & Temperature \\
\hline R-5 & 2 & 38 & 5027 & 3.3 & \\
\hline $\mathrm{R}-6$ & 6 & 20 & 2124 & 1.4 & \\
\hline $\mathrm{R}-7$ & 6 & 36 & 5542 & 3.6 & \\
\hline $\mathrm{R}-8$ & $\overline{2}$ & 58 & 11310 & 7.4 & \\
\hline \multicolumn{6}{|c|}{ Tank Total } \\
\hline
\end{tabular}


Table 4-1. Riser Configuration with Respect to Lightning for A, BX, and T Farms. (12 sheets)

\begin{tabular}{|c|c|c|c|c|c|}
\hline Riser & Radius In & Feight, in & $\begin{array}{c}\text { Target } \\
\text { Area, } \text { In }^{2}\end{array}$ & $\begin{array}{c}\text { Target Area, } \\
\mathrm{m}^{2}\end{array}$ & ANotes \\
\hline \multicolumn{6}{|c|}{ औ } \\
\hline $\mathrm{R}-1$ & 2 & 14 & 804 & 0.5 & \\
\hline $\mathrm{R}-2$ & 6 & 16 & 1520 & 1.0 & \\
\hline R-3 & 6 & 14 & 1257 & 0.8 & \\
\hline R-4 & 2 & 41 & 5809 & 3.8 & Temperature \\
\hline $\bar{R}-\overline{13}$ & 6 & 60 & 13685 & 8.9 & ENRAF \\
\hline $\bar{R}-5$ & 2 & 14 & 804 & 0.5 & \\
\hline$\overline{R-6}$ & 6 & 16 & 1520 & 1.0 & \\
\hline R-7 & 6 & 18 & 1810 & 1.2 & \\
\hline $\mathrm{R}-8$ & 2 & 54 & 9852 & 6.4 & \\
\hline \multicolumn{4}{|l|}{ Tank Total } & 24.1 & \\
\hline \multicolumn{6}{|c|}{$\ldots$ a } \\
\hline $\mathrm{R}-1$ & 2 & 64 & 13685 & 8.9 & ENRAF \\
\hline $\mathrm{R}-2$ & 6 & 16 & 1520 & 1.0 & Dip Tubes \\
\hline R-3 & 6 & 51 & 10207 & 6.6 & \\
\hline R-4 & 2 & 11 & 531 & 0.3 & \\
\hline R-5 & 2 & 10 & 452 & 0.3 & \\
\hline R-6 & 6 & 11 & 908 & 0.6 & \\
\hline R-7 & 6 & 11 & 908 & 0.6 & \\
\hline R-8 & 2 & 65 & 14103 & 9.2 & Temperafure \\
\hline \multicolumn{5}{|l|}{ Tank Total } & 27.5 \\
\hline \multicolumn{6}{|c|}{ in } \\
\hline R-1 & 2 & 65 & 14103 & 9.2 & ENRAF \\
\hline R-2 & 6 & 20 & 2124 & 1.4 & Dip Tubes/SHMS \\
\hline$R-3$ & 6 & 55 & 11690 & 7.6 & \\
\hline R-5 & 2 & 14 & 804 & 0.5 & \\
\hline R-6 & 6 & 18 & 1810 & 1.2 & \\
\hline R-9 & 2 & 29 & 3019 & 2.0 & \\
\hline R-8 & 2 & 60 & 12076 & 7.8 & Temperature \\
\hline \multicolumn{6}{|c|}{ Tank Total 1 I 29.7} \\
\hline
\end{tabular}


Table 4-1. Riser Configuration with Respect to Lightning fo: $A, B X$, and $T$ Farms, (12 sheets)

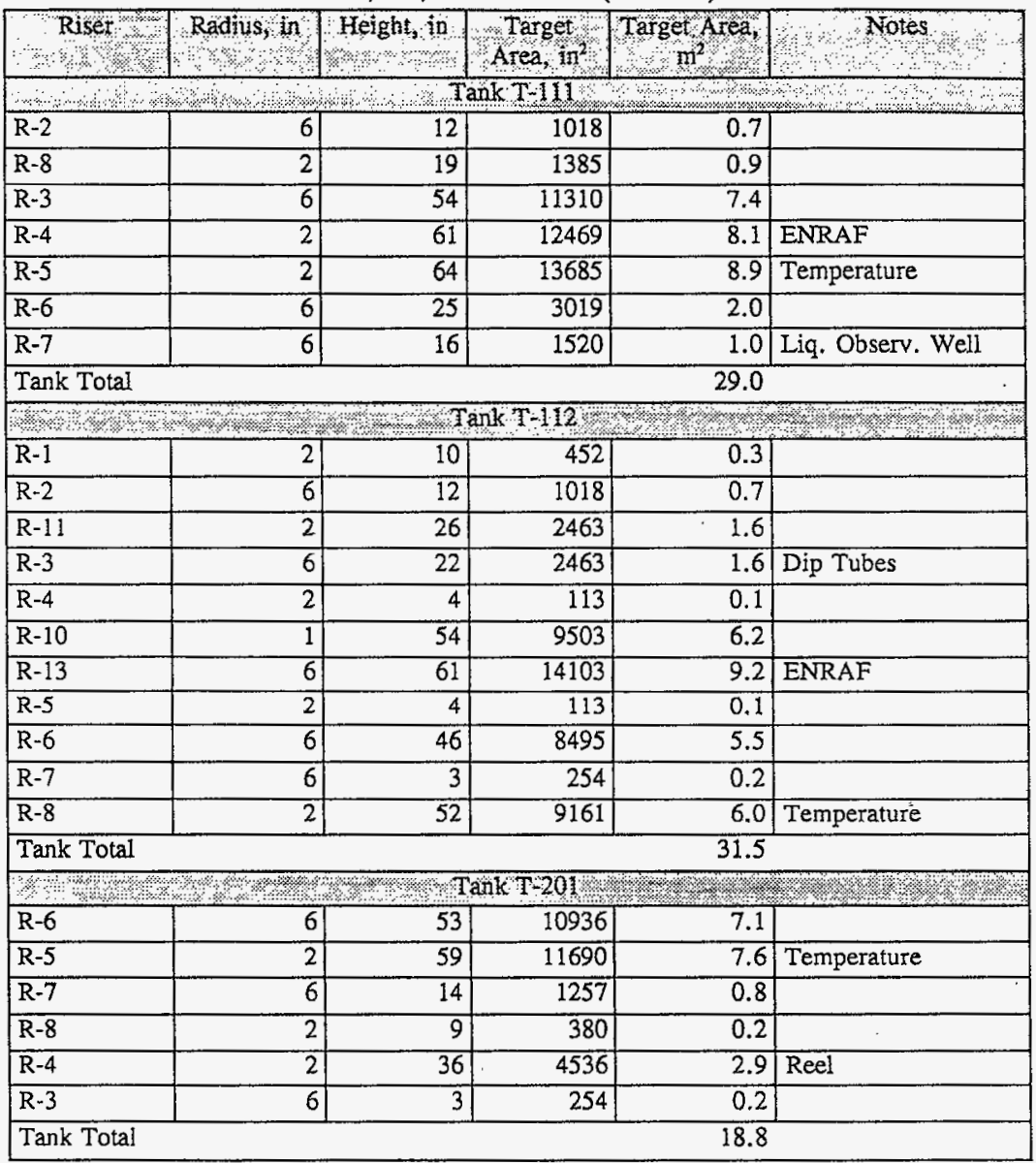


Table 4-1. Riser Configuration with Respect to Lightning for A, BX, and T Farms. (12 sheets)

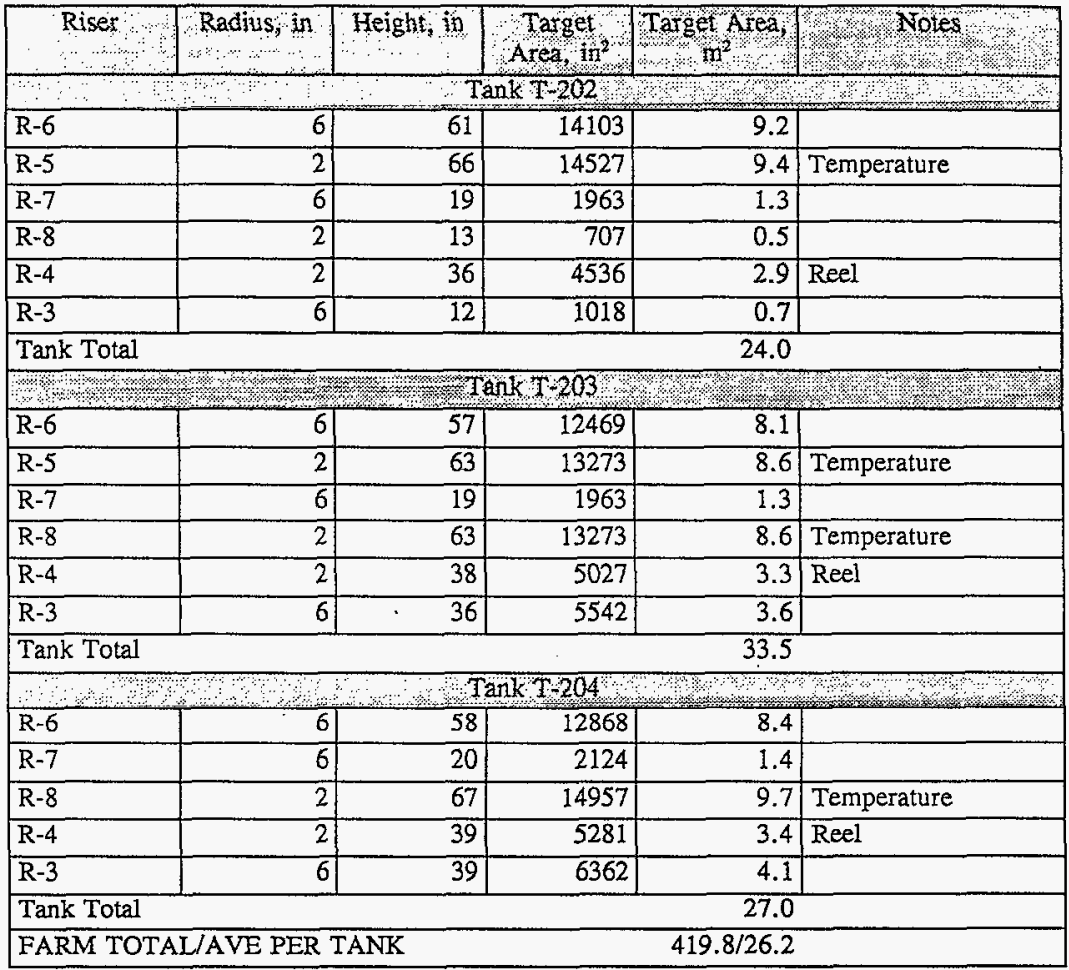

Notes:

ENRAF is a level detector manufactured by the ENRAF Corporation.

FIC is a level detector manufactured by the Food Instrument Corporation.

Temperature is a thermocouple tree or other temperature monitoring device.

Reel is a manual liquid level detector. SHMS is Standard Hydrogen Monitoring System. 


\subsection{LIGHTNING-RELATED ATTRIBUTES OF TANK WASTE}

This document is not intended to be an all encompassing review of waste characteristics. But rather it is to identify those special issues that are related to lightning.

There are three issues of concern with respect to the waste: flammable gas, liquid organic complexants on the waste surface, and organic complexants in the sludge. There is ongoing work to understand further the behavior of the waste with respect to each issue. For example, WHC-SD-WM-SARR-015 (Heubach 1996) is being revised to calculate better how much flammable gas may be generated in the tanks to bound better the frequency of how often a tank can have concentrations of flammable gas in the headspace either in excess of the Lower Flammability Limit (LFL) or 25 percent of the value. Brown and Stout (1996) reported headspace measurements of flammable gas concentrations in 22 SSTs using grab sample results, Standard Hydrogen Monitoring System (SHMS) data, and sniff data from industrial hygiene data sheets. Of 253 grab samples, 37 in six tanks exceeded 500 ppm while only 8 in two tanks exceeded $1000 \mathrm{ppm}$. While these data may be encouraging, not enough information is available to definitively quantify the amount of time that head space concentrations in excess of 25 percent of LFL exist under normal conditions.

\subsection{GRE AND WEATHER/WASTE OBSERVATIONS}

Lightning is associated with thunderstorms which occur in low atmospheric pressure. It has been observed from instrument response and verified mathematically that some tanks have level increases when atmospheric pressure is low because the gas contained in the waste expands. Some information was collected from SY-101 from late 1989 to 1991 (Strachan 1991). The conclusion drawn was "...there is no correlation between the pressure variations and the start of a gas release event." Among other things, Whitney et al. (1996) presented a series of graphs in Appendix F which tracked atmospheric pressure and waste level in 1995. In particular F-7 (S-103 for October 18 to November 19), F-8 (S-106 for October 18 to November 19), F-10 (S-107 for November 1 to November 29), F-13 (S-111 for October 31 to December 1), F-20 (U-103 for November 14 to December 30), F-23 (U-105 for November 14 to December 15), and F-28 (U-109 for October 9 to November 21) show the relationship. In general the changes are in the order of $0.5 \mathrm{in.}$ in an $80 \mathrm{ft}$ tank. If the level change is uniform across the tank, $0.5 \mathrm{in}$. is equal to about $200 \mathrm{ft}^{3}$ of increased waste volume. In general most of the barometric pressure changes were $0.2 \mathrm{in}$. $\mathrm{Hg}$. However, between December 9,1995, and December 12, 1995, a very large pressure swing (almost $1.5 \mathrm{in} . \mathrm{Hg}$ ) occurred. Waste level increased with decreasing pressure consistent with previous data. Four of the DSTs (103-AN, 104-AN, 105-AN, 101-AW) experienced increased $\mathrm{H}_{2}$ concentrations on December 12. The first three tanks had increases in the order of $200 \mathrm{ppm}$ while $101-\mathrm{AW}$ went from $790 \mathrm{ppm}$ to $2110 \mathrm{ppm}$. (As a point of reference $10,000 \mathrm{ppm}$ is roughly equivalent to 25 percent of LFL.) There was no thunderstorm associated with this low pressure system. 
While there is a cause-effect relationship between atmospheric pressure and entrained gas, it does not appear that even significant weather perturbations would cause a single SST to release adequate volumes of gas to cause the head space concentrations to reach the Lower Flammability Limit. The viscosity of the waste as well as the surface tension and the diffused nature of entrained flammable gas in the waste tend to keep the gas from creating a Gas Release Event (GRE) when barometric pressure changes. Since the phenomenology of GREs is not yet fully understood, this paper assumes a lightning strike anywhere on a farm with a flammable gas tank can cause ignition in a tank with dome space concentration in excess of the Lower Flammability Limit. It also presents the methodology for calculating the probability of ignition. Further work needs to be done to determine which tanks have a credible ignition scenario.

\subsection{EQUATIONS}

A second aspect of lightning and potential flammable gas is the calculational technique to determine whether ignition is credible. The probability of any of the 149 SSTs having dome space concentration in excess the LFL coincident with a lightning flash is the summation of each of the tanks' probabilities. In other words:

$$
P_{i g}=\sum_{i=1}^{i=149} \text { Freq }_{t i} \times P_{t i}
$$

Where: $P_{i z}$ is the probability of ignition of any tank, Freq is the flash frequency affecting tank $i$ in flash/tank/year, $P_{\mathrm{L}}$ is the probability of tank $i$ having a concentration of greater than the Lower Flammability Limit (e.g., the fraction of a year that the concentration exists in the tank). One can assume a uniform frequency and Freq ${ }_{\mathrm{wi}}$ is a constant for all the tanks. Or one can do a tank-by-tank calculation with tank-specific target areas. Or one can calculate on a farm-by-farm basis. In this case, using $0.06 \mathrm{fl} / \mathrm{km}^{2} \mathrm{yr}$ and $0.02 \mathrm{~km}^{2}$ for a farm, Freq is $0.001 \mathrm{fl} / \mathrm{farm} / \mathrm{yr}$. Using this frequency, equation (5-1) can be simplified to:

$$
P_{1 g}=\text { Freg } \times \sum_{i=1}^{i=149} P_{t I}
$$

One can than assign a probability that is a limit such as $P_{i g}$ must be less than $10^{-6}$. If the frequency of any one tank being affected because of a strike on the farm is $10^{-3}$, and if the summation of the probability of each tank on the farm exceeding LFL is less than $10^{-3}$ or less than about 8 hours in a year, then the probability of any tank ignition is incredible.

The same general approach can be used with respect to the possibility of initiation of organic-nitrate reaction.

$$
P_{\text {acr }}>\left(1.0-P_{d}\right) \times \text { Freq }
$$


Where $\mathrm{P}_{\text {scc }}$ is an acceptable probability of an occurrence of initiation of an organic-nitrate reaction (e.g., $10^{-6}$ ), $P_{0}$ is the probability that the energy of a lightning strike will be dissipated without ignition, and Freq is the assumed frequency of a lightning strike on a tank. If Freq is less than $10^{-6} \mathrm{fl} / \mathrm{km}^{2} / \mathrm{yr}$, then it does not matter if the waste can effectively dissipate the energy without ignition. Or if $P_{d}$ is greater than $999,999 / 1,000,000$ (the characteristics of the waste are such that the energy is essentially always dissipated), simply stated for this purpose, one does not care if a tank is struck once a year. Equation 5-3 can be solved for either Freq or $P_{d}$.

Based upon a Hanford-area flash frequency of $0.06 \mathrm{fl} / \mathrm{km}^{2} / \mathrm{yr}$ and a tank target area of $5 \mathrm{x}$ $10^{-5} \mathrm{~km}^{2}$, the probability of a tank riser being struck is $3 \times 10^{-6} / \mathrm{yr}$. That would suggest that if the energy can be dissipated $2 / 3$ of the time without ignition either from the riser to ground or through the waste, the overall result is acceptable.

\subsection{ORGANIC PHENOMENOLOGY}

Solvents. There are few tanks with identified organic solvent. Of the 67 tanks which have had vapor space sampling analysis done through April 1996, up to 7 have had indications of a solvent pool of $2 \mathrm{~m}^{2}$ or greater. Of these, one has been verified through photography as having an organic pool on its surface (C-103). Photographs of the surface of a second tank (BY-108) show a dry surface suggesting that organic solvents may be contained within the solid waste. There are no photographs of the other tanks' surfaces. The sampling program is set up to first sample those tanks and farms that are more likely to contain organic solvents based on historical data. The vapor sampling program is scheduled to continue for about two more years until all SSTs have been sampled. Even if one assumes the same rate of finding tanks with possible organic pools, one would expect to find only 8 or 9 more tanks $(7 / 67$ or 10 percent of 82 remaining SSTs).

Fauske (1996) notes that a spark of a modest amount of energy $(10 \mathrm{~J})$ is required to ignite an organic solvent pool. While a typical lightning stroke would generate a spark larger than that needed for ignition, it is extremely improbable that the bulk of the energy would be applied to this one, critical gap. But given the critical gap and spark in one of the few tanks with organic solvent on the waste surface, Meacham et al (1995) demonstrated that for at least one tank (C-103), the fire self-extinguishes at the oxygen extinguishment limit.

Organic Complexants. As discussed below, ignition in an organic complexant tank requires a fuel-rich, low moisture condition. The issue of what an appropriate criteria should be for evaluating the safety of organic tanks is being evaluated. There are 20 SSTs which are on the Organic Watch List because it is assumed they have greater than 3 w\% Total Organic Carbon. Webb et al. (1995) determined that all except 13 SSTs were safe and those 13 were conditionally safe. For purposes of this report, 30 tanks or $20 \%$ of the total are assumed to have the requisite conditions. 
Fauske (1996) points out that a spark of $3.3 \mathrm{~J}$ is required to ignite organic complexant in the waste. He goes further to state, "...the short duration (microsecond time scale) prevents sustained combustion prior to the dissipation of the spark energy." For one example, "...the critical ignition time is of the order of $1 \mathrm{~s}$." And he further states, "...the waste must be essentially dry for such ignition sources to be effective. Small quantities of water will prevent the contact temperatures from reaching the ignition temperature, even for stoichiometric mixtures." With respect to waste moisture content, Fauske et al. (1995) state, "Again, a moisture concentration greater than 20 weight percent (wt\%) will prevent combustion for all fuel-oxidizer concentrations." If the moisture content is less than $5 \mathrm{wt} \%$, an ignition source of $1200 \mathrm{~J} / \mathrm{gm}$ would initiate sustained combustion. A fuel-moisture relationship is defined by a line:

$$
w t \% \text { TOC }=4.5+17\left(x_{w}\right)
$$

where wt \% TOC is the weight per cent of total organic carbon (on a wet basis) and $x_{w}$ is the fraction of free water in the waste. Values of the relationship above the line are susceptible to ignition while combinations below the line are unlikely to ignite.

The fact the waste is in general moist serves to temper energy deposition from lightning. About $968 \mathrm{Btu} / \mathrm{lb}_{\mathrm{m}}$ is the latent heat of vaporization. Since $1056 \mathrm{~J}$ equals $1 \mathrm{Btu}$, about $1 \mathrm{MJ}$ $\left(10^{6} \mathrm{~J}\right)$ is required to vaporize $1 \mathrm{lb}_{\mathrm{m}}$ or $453 \mathrm{~g}$ of water, not including the energy required to heat the water from ambient to the boiling temperature. This is about $1000 \mathrm{~J}$ for $0.5 \mathrm{~g}$. Uman in Appendix A to Cowley and Stepnewski (1994) discusses the two forms of energy deposition: arc and ohmic heating. He notes, "A typical lightning transfer 25 coulombs of charge and thus an arc due to lightning between metal electrodes could liberate 250 joules of energy at the arc spot, in a volume certainly less than a cubic centimeter, perhaps as small as a cubic millimeter." While a spark, with 250 joules concentrated in a very small volume and short duration, may not do much vaporization, it is interesting that the amount of energy Uman uses is the amount required to vaporize $0.1 \mathrm{~g}$ or water or $100 \mathrm{~mm}^{3}$. Ohmic heating is different in that a time integral of current squared is used to calculate the energy. Uman notes, "...the action integral $\{$,$\} is typically 5 \times 10^{4} \mathrm{~A}^{2} \mathrm{~s}$ for negative flashes to earth..." Ninety per cent of the energy (which would range from 100 to $10^{7}$ Joules [depending upon waste conductivity]), would be deposited in about 2 liters of waste. For the upper limit of $10 \mathrm{MJ}, 5 \mathrm{~kg}$ of water could be vaporized.

Spark. It was noted in Chapter 3.0 that an indirect effect of a lightning flash could be the ohmic heating of metal in the tank leading to melting and the subsequent dropping of a piece of molten metal into the waste. Fauske (1996) considers that, "... 250 joules alone would be required to produce a molten steel droplet $4 \mathrm{~mm}$ in diameter, which is less than the capillary size of about $6 \mathrm{~mm}$, i.e., the melted material would quickly refreeze in place." A falling spark does not contain enough energy to ignite the organic waste.

Summary. Although there are still refinements ongoing with respect to tanks contents and waste susceptibility to ignition, one can assume $20 \%$ of the SSTs may have organic waste (either solvent or extractant) that could be susceptible to ignition. Concentrated lightning 
energy precisely deposited in the correct tank is more than adequate to create a spark in excess of that which could cause ignition in a tank with either organic solvents on the waste surface or organic complexants in the waste. A surface fire would burn itself out or moisture in the waste in excess of 20 percent would preclude propagation. In addition, some mitigation is recommended.

\subsection{TANK CLASSIFICATION}

For the purposes of determining the proper type of electrical equipment to be used in certain applications, NFPA 497A (1992) has provided a methodology. Huckfeldt (1996) performed the classification for the flammable gas watch list tanks since the question was raised as to what equipment could be used in the tanks during intrusive activities. While this is not directly applicable to the concern over lightning-initiated events, the logic used can be carried over to this evaluation. NFPA 497A (1992) classifies as Class I those areas where flammable concentration of vapors "...may be present... in sufficient concentration to produce an ignitible mixture." Division 1, which is a subcategory of Class I, includes locations where an "...ignitible mixture is likely to be present continuously or intermittently under normal conditions of operation, repair, maintenance, or leakage." Division 2 locations are those where "...ignitible mixture is likely to be present under abnormal conditions, such as failure of process equipment." Flammable mixtures of Hydrogen are Group B. (Group is the categorization of the type of combustible present in the location.)

Huckfeldt (1996) recommends that new equipment installed in the vapor space of the flammable gas watch list tanks be designed and constructed in accordance with Class I, Division 2, Group B, requirements, i.e., for locations where the ignitible mixture is present under abnormal conditions. He states, "This is a conservative position," because electrical breakdowns are rare even for equipment which has not been designed as rigorously as his recommended type.

Equipment that communicates directly "... with the waste where flammable gases may accumulate during operations should be installed to meet the requirements for Class I, Division 1, Group B locations." This approach is consistent with the concept that, even for flammable gas watch list tanks, the risk of a spark occurring when there is an ignitible mixture is small.

While this evaluation has focussed on organic extractants in the waste, Huckfeldt expresses the concern over retained gas in the waste. The basis for the controls Huckfeldt recommends imposing on intrusive work is consistent with lightning issues presented in this report.

\subsection{CONCLUSIONS}

Based on observations over the past year, it appears that low pressure systems will not cause a gas release event coincident with a lightning storm. Further evaluation is needed to be 
completed with respect to the amount of time that tanks have gas concentrations in excess of the LFL. This report presents the methodology to evaluate the data.

There are few tanks with known organic solvent. The probability of lightning striking a riser of a tank with an organic solvent pool is about $3 \times 10^{-6}$ per year for each tank or $3 \times 10^{-5}$ per year if there are 10 such tanks. The probability of a pool ignition is less than the strike frequency because strike frequency includes all risers on a tank with organic solvent. But, as discussed in Sections 4.3 and 4.6, strikes on most risers will not lead to energy entering the waste because of configuration and grounding. This conservatism has not been quantified.

If the moisture content in the organic extractant waste is greater than 20 percent, a fire will not be initiated by lightning energy being deposited in the waste. There is a critical relationship between moisture content and fuel which will support a fire if a lightning strike were to deposit sufficient energy in the waste. The probability of lightning striking a tank with organic-fuel-rich, dry waste is the same as striking a tank with organic solvent. If $20 \%$ of the tanks have susceptible organic extractants, the probability of any of those tanks being struck in a year is less than $10^{-4}$. As with the solvent tanks, the chance of ignition is less than the strike frequency, but not quantified.

\subsection{REFERENCES}

Brown, R. G., R. Stout, 1996, Compilation of Hydrogen Data for 22 Single-Shell Flammable Gas Waich List Tanks, WHC-SD-WM-ER-576, Revision 0, Westinghouse Hanford Company, Richland, Washington

Fauske, H. K., 1996, Assessment of Chemical Vulnerabilities in the Hanford High-Level Waste Tanks, WHC-SD-WM-ER-543, Revision 0, Westinghouse Hanford Company, Richland, Washington.

Fauske, H. K., D. R. Dickinson, R. J. Cash, and J. E. Meacham, 1995, The Contact-Temperature Ignition (CTI) Criteria for Propagating Chemical Reactions Including the Effect of Moisture and Application to Hanford Waste, WHC-SD-WM-ER-496, Revision 0, Westinghouse Hanford Company, Richland, Washington.

Heubach, E. C., 1996, Topical Report on Steady-State Flammable Gas Generation in Waste Tanks, WHC-SD-WM-SARR-015, Revision 1, Westinghouse Hanford Company, Richland, Washington.

Meacham, J. E., D. A. Tumer, J. C. Van Keuren, M. G. Plys, M. Epstein, H. K. Fauske, J.P. Buerlbach, J.M. Grigsby, and A.K. Postma, 1995, Risk from Organic Solvent Fires in C-103 following Interim Stabilization, WHC-SD-WM-SARR-001, Supplement ], Westinghouse Hanford Company, Richland, Washington. 
Webb, A. B., J. L. Stewart, D. A. Tumer, M. G. Plys, B. Malinovic,

J. M. Grigsby, D. M. Camaioni, P. G. Heasler, W. D. Samuels, J. J. Toth, 1995 , Preliminary Safety Criteria for Organic Watch List Tanks at the Hanford Site, WHCSD-WM-SARR-033, Revision 1, Westinghouse Hanford Company, Richland, Washington

Whitney, P. D., N. E. Wilkins, N. E. Miller, P. A. Meyer, M. E. Brewster, 1996, Flammable Gas Data Evaluation Progress Report, WTSFG 96.1, Pacific Northwest National Laboratory, Richland, Washington. 
WHC-SD-WM-ES-387, Rcv. 0

This page intentionally ieft blank. 


\subsection{CONCLUSIONS/RECOMMENDATIONS}

\subsection{CONCLUSIONS}

1. Lightning flashes in the $200 \mathrm{E}$ and $200 \mathrm{~W}$ areas are less than $0.06 \mathrm{fl} / \mathrm{km}^{2} / \mathrm{yr}$. This is based on ten years of actual data from the Bureau of Land Management and Global Atmospherics, Inc.

2. Based on over 600 ground flashes, peak current for the $99^{\text {th }}$ percentile flash is 100,000 amps.

3. The tanks probably serve as electrodes during a lightning event and, as such, can be affected by a strike anywhere on the farm. The effect of particular concern is for flammable gas.

4. With respect to organics, the paths into tanks leading directly to waste do not present very large targets for lightning. Detailed evaluation of the risers demonstrates that a farm-by-farm approach yields realistic target area values and allows a focussed approach on potential mitigation for those few tank-riser combinations that could a direct path for a significant portion of lightning current into the waste.

5. While the waste shows some response to changing weather (i.e., level changes in response to atmospheric pressure), it appears quite unlikely that a low pressure system can cause a significant gas release event coincidental with lightning creating a spark in an affected tank.

6. Although a detailed cost and schedule estimate for a complete lightning protection system for each tank farm was not done, based on the experience at 101 SY, such a system would cost several million dollars and may create operational challenges for characterization and retrieval of tank waste.

7. Because of the extremely low probability of lightning strike creating an unacceptable event (such as an organic fire) in a tank, complete lightning protection (such as a catenary system) is not warranted.

8. The construction industry practice of bonding down-conductors to reinforcing steel in concrete structures combined with the few reported incidents of significant problems with lightning affecting such buildings allow one to conclude that the likelihood of dome collapse or other major structural problem directly from a lightning strike is extremely unlikely or incredible. 
9. A review of industry standards and guides in conjunction with field measurements point out that the lightning protection for the waste tanks meets the intent of appropriate standards, in particular NFPA 780 (1995). It is anticipated that future activities will continue in compliance with codes and standards.

\subsection{RECOMMENDATIONS}

1. Lightning mitigation should be done in a cost-effective manner. This includes putting air termina's on appropriate light poles and assuring adequate clearances between the electrical ground for any of the farms and existing lightning ground system. This would provide incremental protection to the tank contents.

2. Tank risers with unacceptable riser-to-ground resistance measurements (particularly those which communicate with the waste) should be corrected. This will provide some assurance the risers will divert the energy from a lightning strike to the ground rather than to the tank and/or waste.

3. Further evaluation of the tank characteristics with respect to lightning in the form of RF testing should not be done at this time because of the uncertainty added by subtle as-built differences among the tanks. These differences can cause significant structure response variations, as pointed out in Schnetzer et al. (1995).

4. For those tanks that have waste that is very susceptible to ignition and which have risers that do not meet the acceptance criteria for ground resistance, consideration should be given to putting a grounded, metal structure over those risers that have equipment extending into the waste. 
WHC-SD-WM-ES-387, Rev. 0

APPENDIX A

CODE APPLICABILITY

A-1 
WHC-SD-WM-ES-387, Rev. 0

This page intentionally left blank. 


\section{APPENDIX A}

\section{CODE APPLICABIITY}

In reviewing a list of codes, standards, and recommendations, it appears as if the most applicable is National Fire Protection Association, NFPA 780, STANDARD FOR THE INSTALLATION OF LIGHTNING PROTECTION SYSTEMS, 1995 Edition.

\section{DOE ORDER 6430.1, General Design Criteria}

Paragraph 1630-5 of Section 1630, "Exterior Electrical Utility Services," states, "Lightning protection systems shall comply with NFPA-78...A risk assessment using the guide in Appendix I of NFPA-78 shall be made of these buildings to determine the risk of loss due to lightning." Note that Appendix I in NFPA 78 has become Appendix H of NFPA 780.

\section{API RECOMMENDED PRACTICE 2003}

This Practice addresses tank vehicles, marine operations, storage tanks, miscellaneous electrostatic hazards, lightning and stray currents. It does not address underground storage tanks explicitly.

The petroleum industry's tanks are generally metal and above ground. So most of the discussion revolves around masts and overhead ground wires. It mentions wood, brick, tile, concrete structures in the final paragraph of 6.4 and suggests the protection techniques used for tanks, tankers, etc., is applicable for these other types of structures. Once again, it is not addressing underground facilities specifically. It notes the protection zone concept is consistent with NFPA 78 (the predecessor to NFPA 780).

NFPA 780

The following are some applicable definitions from the Standard:

Authority Having Jurisdiction. The organization, office, or individual responsible for approving equipment, an installation, or a procedure. (This is further discussed in Appendix A, Explanatory Material. A-2-2 states, "The phrase 'authority having jurisdiction' is used in NFPA documents in a broad manner, since jurisdictions and approval agencies vary, as do their responsibilities. Where public safety is primary, the authority having jurisdiction may be a federal, state, local, or other regional department or individual...")

Listed. Equipment or materials included in a list published by an organization acceptable to the authority having jurisdiction and concerned with product evaluation that maintains periodic inspection of production of listed equipment or materials and 
whose listing states either that the equipment or materials meets appropriate standards or has been tested and found suitable for use in a specific manner.

Metal-framed Structure. A structure with electrically continuous structural members of sufficient size to provide an electrical path equivalent to that of the lightning conductors covered in this standard. Vapor Openings. Openings through a tank shell or roof above the surface of the stored liquid. Such openings might be provided for tank breathing, tank gauging, fire fighting, or other operating purposes.

Zone of Protection. The zone of protection is that space adjacent to a lightning protection system that is substantially immune to direct lightning flashes.

The following are specific, applicable paragraphs of the standard:

Chapter 4.0 Protection for Miscellaneous Structures and Special Occupancies. 4-6 Concrete Tanks and Silos. Lightning protection systems for concrete (including prestressed concrete) tanks containing flammable vapors, flammable gases, liquids that can produce flammable vapors... shall be provided with either external conductors or with conductors embedded in the concrete in accordance with Chapters 3.0 or 6.0 .

Chapter 6.0 Protection for Structures Containing Flammable Vapors, Flammable Gases or Liquids that Can Give Off Flammable Vapors.

\section{6-1 Reduction of Damage.}

6-1.1 This chapter applies to the protection of structures containing flammable vapors, flammable gases or liquids that can give off flammable vapors. (Appendix A Explanatory Material notes in A-6-1.1, "This chapter applies to flammable or combustible liquids such as gasoline, diesel, jet fuel, fuel oil, or crude oil stored at atmospheric pressure.)"

6-1.2. Certain types of structures used for the storage of liquids that can produce flammable vapors, or used to store flammable gases are essentially self-protecting against damage from lightning strokes and need no additional protection. Metallic structures that are electrically continuous, tightly sealed to prevent the escape of liquids, vapors, or gases, and of adequate thickness to withstand directs strokes (sheet steel $3 / 8$ in. or greater)... are inherently self-protecting...

6-2 Fundamental Principles of Protection. Protection of these structures and their contents from lightning damage requires adherence to the following principles:

(c) Structures and all appurtenances (e.g., gauge hatches, vent valves) shall be maintained in good operating order. 
(e) Potential spark gaps between metallic conductors shall be avoided at points where flammable vapors can escape or accumulate.

\section{6-3.3 Rods, Masts, and Overhead Ground Wires.}

6-3.3.1. The zone of protection of a lightning mast is based on the striking distance of the lightning stroke (the distance over which the final breakdown of the initial stroke to ground, or to a grounded object, occurs). Since the lightning stroke can strike any grounded object within the striking distance of the point from which final breakdown to ground occurs, the zone of protection is defined by a circular arc concave upward. The radius of the arc is the striking distance and the arc passes through the tip of the mast and is tangent to the ground.... The striking distance is related to the peak stroke current and thus to the severity of the lightning stroke; the greater the severity of the stroke, the greater the striking distance. In the vast majority of cases, the striking distance exceeds $30 \mathrm{~m}$ (100 ft). Accordingly, the zone based on a striking distance of $30 \mathrm{~m}(100 \mathrm{ft})$ is considered to be adequately protected...Increasing the height of a mast above the striking distance will not increase the zone of protection. \{The zone of protection can be calculated algebraicly by the following equation.

$\mathrm{d}^{2}=h \times(200-h)$ where $d$ is the horizontal distance from the mast to the edge of the zone of protection and $h$ is the height of the mast.

6-3.3.4. Masts of wood, used either separately or with ground wires, shall have an air terminal extending at least $0.6 \mathrm{~m}(2 \mathrm{ft})$ above the top of the pole, securely attached to the pole, and connected to the grounding system....For metallic masts, the air terminal and the down conductor shall not be required.

\section{APPENDIX H RISK ASSESSMENT GUIDE}

H-1 General H-1.1. This lightning risk assessment guide is prepared to assist in the analysis of various criteria to determine the risk of loss due to lightning. As a guide, it is not possible to cover each special design element that may render a structure more or less susceptible to lightning damage. In special cases, personal and economic factors may be very important and should be considered in addition to the assessment obtained by using the guide.

\section{H-2 Determining the Risk.}

$R($ Risk $)=\frac{A+B+C+D+E}{F}$

A-Type of Structure $=$ building housing the storage of hazardous material 10

B-Type of Construction $=$ reinforced concrete 1 
C-Relative Location $=$ underground/structures in areas with higher structures 1

D-Topography $=$ On flat land 1

E-Occupancy and Contents $=$ Explosive ingredients 10

Combustible materials 5

F-Iightning Frequency Isokeraunic Level $=0-5 \quad 9$

$\mathrm{R}=\frac{10+1+1+1+10 \operatorname{Cor} 5)}{9}=2-2.5=$ Light to Moderate Risk Value 
NFPA 30

The Flammable and Combustible Liquids Code in paragraph 2-7, "Sources of Ignition," directs the user to NFPA 78 (the predecessor of NFPA 780) to obtain information on lightning protection for tank storage (both above ground and underground).

NFPA 50A/50B

Neither NFPA 50A, "Gaseous Hydrogen Systems at Consumer Sites," nor NFPA 50B, "Liquefied Hydrogen Systems at Consumer Sites," alludes to lightning protection. 
WHC-SD-WM-ES-387, Rev. 0

This page intentionally left blank. 
WHC-SD-WM-ES-387, Rev. 0

APPENDIX B

LIGHTNING-RELATED OCCURRENCE REPORTS 
WHC-SD-WM-ES-387, Rev. 0

This page intentionally left blank. 


\section{APPENDIX B}

\section{LIGHTNING-RELATED OCCURRENCE REPORTS}

A search of the occurrence report data base was conducted on the word "lightning." It resulted in 33 reports over six years (1990 to 1995). Two were discounted because they were work-practice related. One had to do with a lightning arrestor. Four were reports of grass fires. Ten were associated with power outages elsewhere on site or inadvertent activation of railroad track grade crossing barricade arm.

(RL-WHC-KHFLEETOP-1994-0006 noted three spurious activations of an arm from May 20 through May 23, 1994, because of failed diodes possibly due to ..." heavy rain/lightning...") Sixteen reports were identified as being related with the $200 \mathrm{E}$ and $200 \mathrm{~W}$ areas.

On June 29,1991 , shortly after 3:00 pm, five events related to a passing storm caused occurrence reports. At 1510 (RL-WHC-TANKFARM-1991-1026) electrical power was lost to all East Tank Farm facilities. On page 4 of the report the evaluation includes a note, "The 200 East Area power failure is also documented from a site wide perspective in an Occurrence Report (RL-WHC-200EM-1991-1025) issued by Operational Site Services." Also at 1510 (RL-WHC-GROUT-7991-1003) "lightning struck and disrupted the main power to the grout processing facility causing the ventilation system to shutdown (sic)." The Description of Cause includes, "Lightning struck and knocked down the main power that was supplying the 200 East area and Grout." In Description of Occurrence the power supply is identified as 243-G9. At 1515 (RL-WHC-WHC200EM-1991-1025, the report referred to above) noted, "...lightning apparently struck near the $13.8 \mathrm{kV}$ overhead lines C8-L6 and C8-L7." At 1535 ( $R L-W H C-B P L A N T-1991-1014$ ) stated, "All facilities at B Plant/WESF had a loss of primary electrical power supply. Lightning from an electrical storm disrupted feeders C8-L6 and C8-L7." These are the same feeders identified in the previous report. There is a twenty minute discrepancy in the times of the reports. Ten minutes later at 1540 (RL-WHC-SOLIDWASTE-1991-1002), "Following the lightning storm, Tank Farm personnel checked the status of facilities and discovered that the 213-W building exhauster was shut down." One can understand that from the time of the first report (1510) until this report (1540) the operators were touring facilities and there would be a lag before some items may be identified and reported to the shift manager who would then decide reportability. It appears very likely that all five of these reportable occurrences are from a single strike on the $13.8 \mathrm{kV}$ line.

On August 6, 1991, five more reportable occurrences happened in the late afternoon. At 1730 (RL-WHC-ANNAILAB-1991-1015), "Electrical storm activity caused power loss at several facilities in the $200 \mathrm{E}$ and $200 \mathrm{~W}$ areas." This included the Jaboratory where "A total momentary power loss due to an electrical storm resulted in a low intake vent alarm... Building evacuated as precautionary measure due to no air supply to CAMs." At 1743 (RL-WHC-BPLANT-1991-1023), "... at approximately 1740, B Plant experienced a momentary power fluctuation due to a lightning strike on a site main feeder system." At the same time (RL-WHC-WHC2OOEM-1991-1035), "Lightning caused the $13.8 \mathrm{KV}$ breakers 
C8X1 and C8X4 to trip, relay action closed breakers C8X1 and C8X4." At 1747 (RL-WHC-PUREX-1991-1039), "...a power interruption at the UO3 Plant had occurred." When the plant contacted the PFP Power Operators Control Room, they were, "...informed that all of the 200 West area had suffered the power interruption..." Finally at 1754 (RL-WHC-GROUT-1991-1005), "...lightning disrupted the main power to the grout processing facility." The report states the event happened at 1745 , very close to the same time as the event at the UO3 Plant (1747). Without further investigation it is difficult to say whether one or two flashes caused the five reports.

Unrelated to the other ten reports from 1991 is RL-WHC-WHC200EM-1991-1027, which occurred at 0255 on July 13,1991 . In this instance, "Lightning caused the $13.8 \mathrm{KV}$ breaker $\mathrm{C} 4 \times 18$ to trip, relay action close breaker C $4 \times 18 . "$

On June 28,1992 , a late evening storm resulted in three occurrence reports. At 2107 ( $R L-W H C$-WHC2OOEM-1992-0038), " $\ldots 13.8 \mathrm{kV}$ breakers were tripped by protective relay . action and successfully reclosed. This caused momentary power outage to all connected loads on the $13.8 \mathrm{kV}$ lines C8-L3 and C8-LA. The facilities involved were...242UA,...284-W 241 Tank Farm,..." The Time Discovered for the next report (RL-WHC-PUREX-1992-D073) is 2150. However the text states that alarms were received at 2113 , closer to the time of the previous report. Also it notes the tie breaker between the main power feed lines for the 224-UA building has closed. It is probably the case that in the previous report, the reference to 242UA should have be to 224UA. In a fashion similar to the previous report, the Discovery Time is 2150 for $R L-W H C-T A N K F A R M-1992-0051$. In the report, it notes that, "...at 2107 hours, a lightning strike on a $500 \mathrm{KVA}$ transformer caused a 45 second power loss on the C8-L3 and C8-IA power lines serving the 200 West area." This is identical to the description to the first case. The reason for the later discovery time is the fact the operations personnel surveyed the area and found equipment not operating. As in previous events, it appears that a single lightning strike caused three reports.

The following occurrence reports also were associated with the June 28,1992 , storm but not at the 200 area and are included here for information:

RL-WHC-WHC300EM-1992-0030 "At 2015... 13.8 kV breaker...tripped by protective relay action. This caused a power outage to all connected loads on $13.8 \mathrm{kV}$ lines C3-L2, C3-L3, C3-L5."

RL-WHC-WHC600EM-1992-022 "A total building primary power failure occurred due to a power outage...Lightning struck a transformer causing a power outage."

RL-WHC-WHC600EM-1992-0023 "At 2220...the 100 Area Fire Station notified the Dispatcher that there was a loss of power to their facility...(L)ightning struck a section of $13.8 \mathrm{kV}$ line $\mathrm{C} 8-\mathrm{L} 6 . . . "$ 
RL-WHC-WHC600EM-1992-0025 The June 28, 1992, thunderstorm resulted in range fires that caused the generation of a occurrence the next day.

RL-WHAC-UO3-1994-0003 may not have been a direct result of lightning. On February 13,1994 , at 1040, management discovered that some recorders were not operating and a report needed to be generated. However, the cause of the malfunction was not known. "Several electrical, wind, and rain storms have occurred at the UO3 facility within the last month. During these weather disturbances, spiking has been observed on the two (2) recorder channels..." (Description of Cause) In Description of Occurrence there is a note, "On Thursday afternoon, $2 / 17 / 94$, during a lightning storm, the chart recorders R-1, R-2 and R-3 noted spikes..."

Finally, $R L$-WHC-BPLANT-1995-0047 was reported October 4, 1995, at 0900. However the event occurred on September 28, 1995, at approximately 1420 . "...(A) lightning bolt was seen near the front of the 271-B facility... The investigation...determined that the cause (of . the alarms) was due to failure of the I/P controller..."

There have been at least six separate lightning strikes over a six year period which resulted in sixteen occurrence reports in the 200 East and 200 West areas. One report, RL-WHC-UO3-1994-0003, does not identify a specific time to narrow in on certain storm, but does include references to electrical storms in the area. Thunderstorms in the Hanford area in February are rare. Global Atmospherics, Inc., detected about 15 to 20 flashes in February 1994, none in any other year.

As noted there were six occurrence reports from the 200 area on June 28,1992 , and four more from the rest of the site related to lightning. There are two other days on which multiple reports were generated identifying lightning as a cause. These were not in the 200 area.

RL-WHC-308-1990-0025 On September 7, 1990, "Lightning strike on BPA grid resulted in a power fluctuation that automaticaliy shut down the facility HVAC computer."

RL-WHC-FFTF-1990-0026 A1so on September 7, 1990, "Lightning strikes on the Bonneville Power Administration $230 \mathrm{KV}$ power distribution grid led to the interruption of electrical power to the plant..."

RL-WHC-WHC100EM-1992-0006 on July 20, 1992, "At 0721..1ightning apparently struck an insulator on the $13.8 \mathrm{kV}$ Line C4-Li8."

RL-WHC-WHC600EM-1992-026 ATso on July 20, 1992, "A lightning storm ignited a small grass fire at the intersection of Route 2 North and Route IIA..."

The other five occurrence reports for the site $(30$ valid lightning-related of which 16 are discussed here as associated with the 200 area, eight are identified as being related with common storms or strikes, and one for the grade crossing mentioned because of the ambiguity of the cause) included two 
for grass fires (August 20, 1993, and August 7, 1994) and three for power outages (May 15, 1993, June 11, 1994, and July 10, 1995).

While it appears there is a high number of lightning-related occurrence reports (thirty over six years including 16 related to the 200 area) for the Hanford site considering the relatively few thunderstorm days in an average year, a more indepth review of the information would suggest the site is required to generate multiple reports from events which were initiated by a single flash because of the design of the electrical power distribution system. 
This page intentionally left blank. 